\title{
Peak Separation by Derivative Spectroscopy Applied to FTIR Analysis of Hydrolized Silica
}

\author{
Bernardo J. G. de Aragão*,a and Younes Messaddeq ${ }^{b}$ \\ ${ }^{a}$ Fundação CPqD, Rod. SP 340 Campinas-Mogi Mirim, km 118, 13086-902 Campinas-SP, Brazil \\ ${ }^{b}$ Instituto de Química, Universidade Estadual Paulista, R. Francisco Degni s/n, 14800-900 Araraquara-SP, Brazil
}

\begin{abstract}
A análise espectral só se torna confiável se o espectro é detalhadamente analisado quanto a todos os picos sobrepostos e ocultos. Neste trabalho são descritas as etapas para revelar e separar esses picos na faixa de 3000-4000 $\mathrm{cm}^{-1}$ em três espectros de absorção de infravermelho colhidos na superfície vítrea de fibras ópticas de sílica hidrolizada. A revelação dos picos foi feita com a análise da segunda e quarta derivada dos dados experimentais digitalizados, juntamente com o conhecimento disponível de espectroscopia de infravermelho da interação sílica-água na faixa espectral investigada. A separação de picos foi realizada com ajuste de curva usando quatro modelos distintos. O melhor ajuste foi alcançado com um modelo que descrevia os espectros com uma soma de picos do tipo Gaussiano. Mapas descrevendo os limites de ombro ("shoulder limits") e de detecção foram utilizados para validar os detalhes espectrais revelados.
\end{abstract}

Reliable spectral analysis is only achieved if the spectrum is thoroughly investigated in regard to all hidden and overlapped peaks. This paper describes the steps undertaken to find and separate such peaks in the range of 3000 to $4000 \mathrm{~cm}^{-1}$ in the case of three different infrared absorption spectra of the glass surface of hydrolyzed silica optical fibers. Peak finding was done by the analysis of the second and fourth derivatives of the digital data, coupled with the available knowledge of infrared spectroscopy of silica-water interaction in the investigated range. Peak separation was accomplished by curve fitting with four different models. The model with the best fit was described by a sum of pure Gaussian peaks. Shoulder limit and detection limit maps were used to validate the revealed spectral features.

Keywords: FTIR, silica, water, peak separation, curve fitting

\section{Introduction}

The spectral analysis of materials results frequently in a poorly resolved spectrum due to the existence of highly overlapped and hidden peaks. Overlapping causes spectral line distortion and derives from the finite resolution of the measuring device (e.g. a spectrometer) and from physical factors which are intrinsic to the material investigated. While the former can be solved by increasing instrumental resolution, the later can be reversed only by mathematical methods. ${ }^{1}$ Overlapping due to intrinsic factors is more likely to be observed in spectra of materials with random structures like glass or water, characterized by fewer bands and peak broadening. ${ }^{2-4}$

The first step to investigate the spectrum for hidden and overlapped peaks is to gather all information available on the system under investigation. The second step involves

*e-mail: grbernardo@cpqd.com.br, younes@iq.unesp.br resolution enhancement, which is achieved through the separation of these peaks into their separate components. The third step is curve fitting of the experimental spectrum by a function which is the sum of the individual peaks. The analysis reliability depends strongly on how far these steps are pursued.

The existence and location of overlapped and hidden peaks are found by spectra deconvolution or by spectra differentiation (derivative spectroscopy). ${ }^{5,6}$ In the first method, the measured spectrum is divided by the instrumental function to reverse signal distortion ${ }^{5}$ and this can be conveniently done in the Fourier domain. ${ }^{6,7}$ Several methods have been developed for deconvolution recently, ${ }^{1,8-12}$ spurred mainly by the advance of personal computers. ${ }^{13}$ Deconvolution is performed numerically. It is an unstable process and different strategies have been proposed for stabilization. ${ }^{1}$

The second method involves the analysis of the second $^{6,14}$ or the fourth derivative ${ }^{15}$ of the spectrum. 
Differentiation reveals details of slope change and rate of change in the experimental spectrum which unveils the presence of hidden and overlapped peaks. ${ }^{5,6}$ First and higher order spectrum derivatives can be obtained by successive numerical differentiation of the digitized data according to the following algorithm:

$$
Y_{i}^{\prime}=\frac{Y_{i+1}-Y_{i-1}}{X_{i+1}-X_{i-1}}
$$

where $\left(\mathrm{Y}_{\mathrm{i}+1} / \mathrm{X}_{\mathrm{i}+1}\right)$ and $\left(\mathrm{Y}_{\mathrm{i}-1} / \mathrm{X}_{\mathrm{i}-1}\right)$ are, respectively, the subsequent and preceding data points of the $\left(\mathrm{Y}_{\mathrm{i}} / \mathrm{X}_{\mathrm{i}}\right)$ data point. Since differentiation introduces noise amplification, if necessary, differentiation should be followed by data smoothing. The other option is to use the Savitsky-Golay filter, by which one gets a smoothed derivative of the original spectrum. Procedures for data smoothing are covered in the literature. .,6,16 $^{5}$

Another algorithm obtains a resolution enhanced spectrum similar to a deconvoluted one: ${ }^{5}$

$R_{i}=Y_{i}-k_{2} \cdot Y_{i}^{\prime \prime} \quad$ or $\quad R_{i}=Y_{i}+k_{4} \cdot Y_{i}^{\prime \prime \prime \prime}$

where $Y_{i}$ " and $Y_{i}$ ", are the second and fourth order derivatives, respectively, $\mathrm{R}_{\mathrm{i}}$ is the resolution enhanced signal and $\mathrm{k}_{2}$ and $\mathrm{k}_{4}$ are user selected positive constants. Hint: $\mathrm{k}_{2}$ and $\mathrm{k}_{4}$ should be selected such that $\mathrm{k}_{2} \mathrm{Y}_{\mathrm{i}}^{\prime}$ ' and $\mathrm{k}_{4}$ $\mathrm{Y}_{\mathrm{i}}$ "', are of the same magnitude as $\mathrm{Y}_{\mathrm{i}}$.

Peak separation is achieved by curve fitting, in which the experimental spectrum is fitted by a function which is the sum of the individual peaks with Gaussian or Lorentzian shape, represented by equations (3) and (4), respectively.

$$
\begin{aligned}
& I=A e^{\left[\frac{-\left(v-v_{0}\right)^{2}}{s^{2}}\right]} \\
& I=A\left[1+\frac{\left(v-v_{0}\right)^{2}}{s^{2}}\right]^{-1}
\end{aligned}
$$

Initial guesses for the parameters of peak maximum $v_{0}$ (e.g. in units of frequency, wavenumber or voltage), peak height $\mathrm{A}$ and peak width $\mathrm{s}$ are estimated from the both experimental and resolution enhanced spectrum. It is also common to use peak shapes represented by a sum or a product of Gaussian (equation 5) and Lorentzian (equation 6) peak shapes: ${ }^{17}$

$$
I=f A e^{\left[\frac{-\left(v-v_{0}\right)^{2}}{s^{2}}\right]}+(1-f) A^{\prime}\left[1+\frac{\left(v-v_{0}\right)^{2}}{\left(s^{\prime}\right)^{2}}\right]^{-1}
$$

$$
\begin{gathered}
I=f A e^{\left[\frac{-\left(v-v_{0}\right)^{2}}{s^{2}}\right]} A^{\prime}\left[1+\frac{\left(v-v_{0}\right)^{2}}{\left(s^{\prime}\right)^{2}}\right]^{-1}= \\
B e^{\left[\frac{-\left(v-v_{0}\right)^{2}}{s^{2}}\right]}\left[1+\frac{\left(v-v_{0}\right)^{2}}{\left(s^{\prime}\right)^{2}}\right]^{-1}
\end{gathered}
$$

Factor $\mathrm{f}$ in equations (5) and (6) is the fractional Gauss character of the compound peak shape.

Meaningful resolution is only accomplished as long as the curve fitted spectrum is critically evaluated in regard to the following items: goodness-of-fit, a suitable peak separation criterion and the experience with or the previous knowledge of the system under investigation.

\section{Goodness-of-fit}

The fitted curve has to be as close as to the original spectrum. The difference between both has to be at a minimum, as attested by an appropriate goodness-of-fit test. The discrepancy (DIS), given by equation (7), is frequently evaluated for this purpose. ${ }^{17,18}$ Best fit is accomplished for minimum values of DIS.

$D I S=\sqrt{\frac{\sum_{1}^{n}\left(C F_{i}-E_{i}\right)^{2}}{n}}$

$\mathrm{CF}_{\mathrm{i}}$ is the curve fitted spectrum and $\mathrm{E}_{\mathrm{i}}$ is the experimental one at a particular point; $n$ is the total number of data points of the spectrum.

However, high goodness-of-fit is a necessary condition, but not sufficient for the recovery of the true spectrum. ${ }^{18}$ It is quite usual to achieve low DIS values, but the curve fit proves to have poor correspondence with the original spectrum in regard to number of peaks and peak parameters (height, maximum and width). An additional way to check for the fit is to compare the second and/or fourth derivative curve of the experimental spectrum and those of the curve fitted one. ${ }^{15}$ They should match as close as possible. The reason behind this is that the details of slope change related to the presence of hidden and overlapped peaks should have good correspondence, too. Comparison of the derivative curves can be done visually. ${ }^{15}$ However, in this paper it is proposed to extend the calculation of the DIS values to the derivative curves.

\section{Peak separation criterion}

Two criterions distinguish between different degrees of overlap. A valley or plateau which visually separates two overlapping peaks defines the shoulder limit and is 
expressed mathematically by equation (8). An inflection point in the spectrum that coincides with the maximum of the minor peak defines the detection limit and is expressed mathematically by equation (9). ${ }^{17}$

$Y^{\prime}=Y^{\prime \prime}=0$

$Y^{\prime \prime}=Y^{\prime \prime}=0$

Both the shoulder limit and the detection limit depend strongly on the ratio of peak height, peak width and peak position of two overlapping peaks, in addition to the peak shape. A complete analysis of the limits as a function of these parameters has led to the development of graphs or maps which allow, for a set of parameter values, the determination of the degree of overlapping of two neighbor peaks. ${ }^{18}$ The significance of these maps as to validate a curve fitting model is demonstrated in this study.

\section{Experience with the system under investigation}

The final evaluation of the curve fitted spectrum as to its closeness to the true spectrum has to take into account all what is known by the researcher about the system. ${ }^{17}$ In many cases, additional peaks have to be included in the curve fitting model, even when they do not show up in the derivatives curves. The addition of these peaks may not only increase the goodness-of-fit, but also provide a better physical model for the system. This point in particular is clearly shown in the examples included in this paper.

This paper describes a procedure for peak separation using both second and fourth derivatives in FTIR absorption spectra of hydrolyzed silica optical fibers from 3000 to $4000 \mathrm{~cm}^{-1}$, within the range of hydroxyl $-\mathrm{OH}$ stretching bands. ${ }^{2}$ Despite de many translational and rotational vibration modes of gaseous water, which give rise to a complex infrared spectrum, water in glass has many of these modes almost restrained due to restrictions imposed by the glass environment. Moreover, as already mentioned before, the random structure of liquid water and glass results in fewer infrared peaks, as well as in peak broadening and in peak overlap..$^{2-4}$ For hydrolyzed silica glass in particular the 3000 to $4000 \mathrm{~cm}^{-1}$ range is of special interest, since, as shown in Figure 1 and Figure 2, the peaks below $3500 \mathrm{~cm}^{-1}$ are due to stretching vibrations of free molecular water or water adsorbed on silica; above $3500 \mathrm{~cm}^{-1}$, the peaks are caused by $-\mathrm{OH}$ stretching in silanol $(\equiv \mathrm{Si}-\mathrm{OH}) .{ }^{2}$ The close proximity of these peaks usually results in highly overlapped spectra, requiring resolution enhancement for a correct assessment of the silica-water interaction process.

The spectra presented in this paper were part of a larger research work aiming at correlating the silica-water interaction at the glass surface during ageing with the mechanical resistance of the optical fibers after ageing. ${ }^{19}$ A lot has been published on the effect of water at the glass surface of silica optical fiber and its role on the static fatigue of optical fibers. Some authors believe static fatigue is due
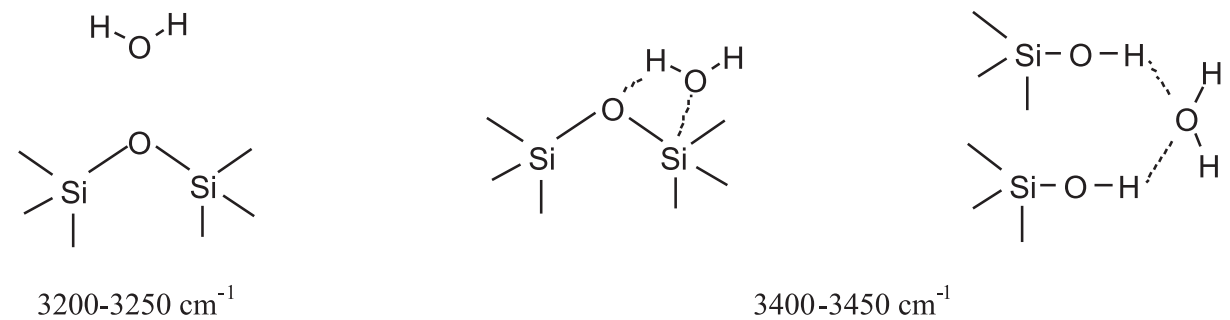

$3400-3450 \mathrm{~cm}^{-1}$

Figure 1. Peaks of free and adsorbed molecular water in silica..$^{19}$ In addition to the above bands, a peak at $3140 \mathrm{~cm}^{-1}$ is also assigned to molecular water in silica rich glasses. ${ }^{26}$

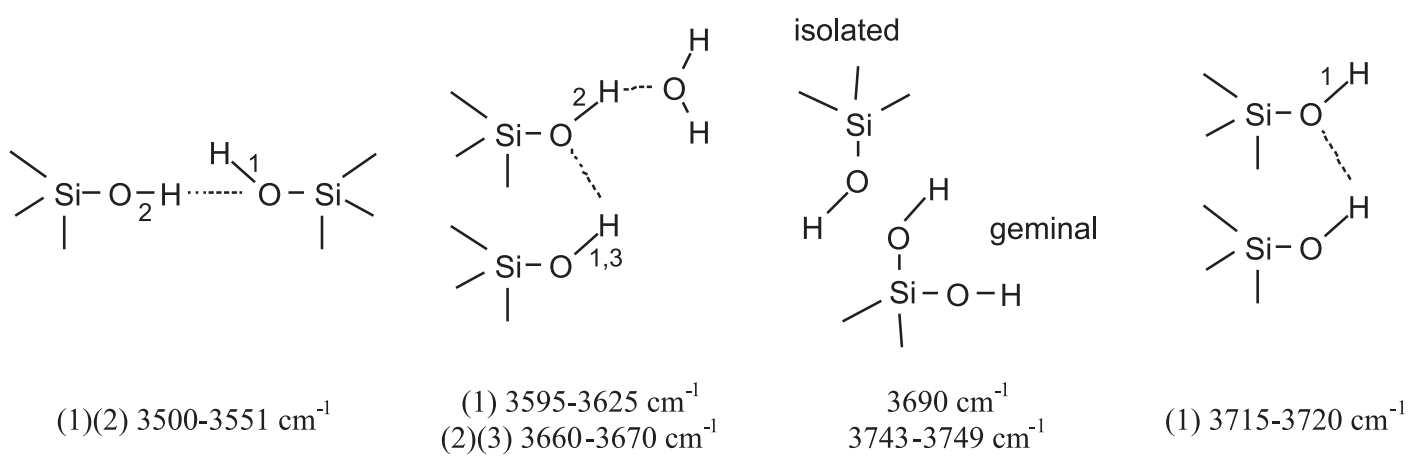

Figure 2. Hydroxyl $-\mathrm{OH}$ stretching bands. ${ }^{19}$ In addition to the above bands, a peak at $3850 \mathrm{~cm}^{-1}$ is due to a combination of various stretching modes. ${ }^{2}$ 
to surface roughening caused by silica dissolution. ${ }^{20-23}$ Others ascribe it to stress relaxation of vitreous silica. ${ }^{24}$ To understand the processes which promote static fatigue, one has to investigate the silica-water interactions which occur in the silica at the fiber surface, especially in regard to the presence of water as free water and/or bound water, which is a less investigated subject in regard to mechanical reliability of optical fibers.

\section{Materials and Methods}

The spectra of three different ageing conditions were analyzed: $i$ ) unaged, ii) after six years of field ageing and iii) after ageing for 14 days at room temperature and under a compressive stress of $0.5 \mathrm{GPa}$. They were collected at the glass surface of a silica optical fiber for telecommunication (125 $\mu \mathrm{m}$ diameter single mode fiber).

The FTIR spectra were collected in absorption mode with a Nicolet Magna-IR infrared spectrometer, Model 550, using a microscope attachment (Spectro-TechM) to scan a micro area of $c a .65 \mu \mathrm{m}$ diameter on the fiber surface. Each spectrum was taken with 256 scans, with a spacing of $32 \mathrm{~cm}^{-1}$. Preliminary spectrum treatment involved smoothing with Fast Fourier Transform Filtering and baseline correction by subtracting a linear baseline fitted between the first and last points.

Data analysis started with the analysis of the second and fourth derivatives of the experimental spectrum for overlapped and hidden peaks. Then a resolution enhanced spectrum was obtained according to equation (2). The resolved peaks allowed for initial guesses of the peak maximum $v_{0}$ and peak width $\mathrm{s}$. The later was taken as the full width at half height of the resolved peaks. The guess for peak height $A$ was the experimental spectrum value at peak maximum $v_{0}$ (Figure 3).

Table 1. Curve fitting models

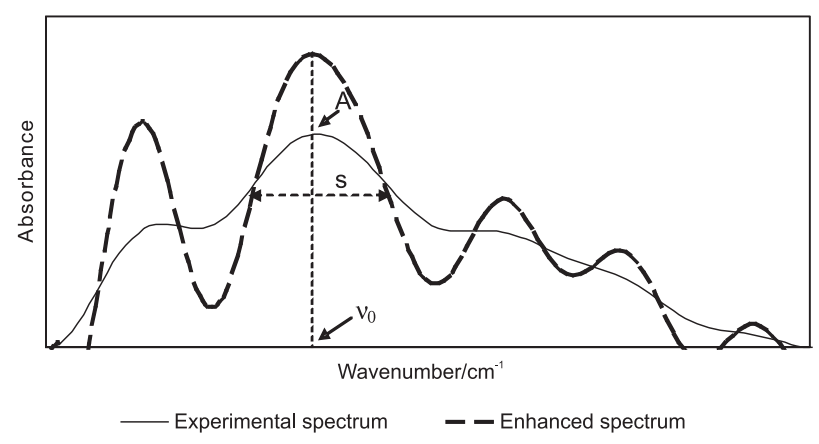

Figure 3. Initial guess for peak maximum $\left(v_{\mathrm{o}}\right)$, peak width $\mathrm{s}$ and peak height $\mathrm{A}$.

For curve fitting, different models were chosen to investigate the best fit and are presented in Table 1.

Figure 4 compares the peak shape of each model for a given set of values for $v_{0}$, A and $\mathrm{s}$. The Lorentzian fraction of Model II did not alter significantly the overall Gaussian peak shape of that model, as it closely resembles the shape of Model I. The peak shape of Model IV shows the characteristic wide base of a purely Lorentzian peak.

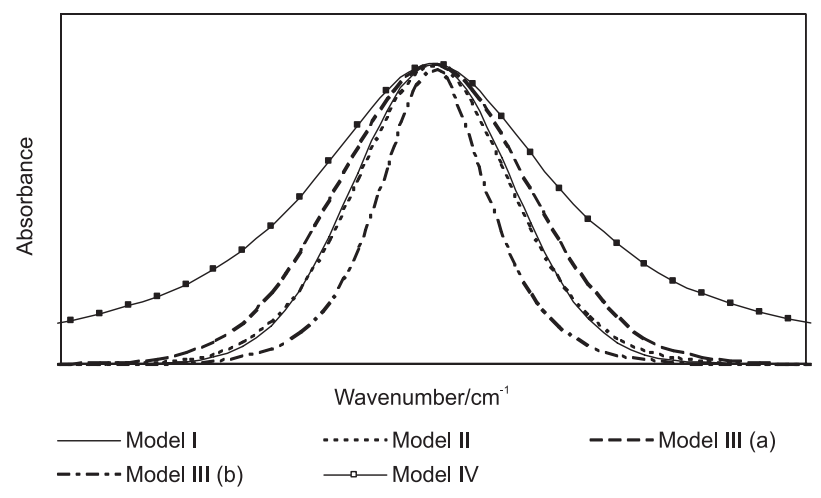

Figure 4. Peak shapes according to curve fitting models.

\begin{tabular}{|c|c|}
\hline Model & Description \\
\hline Model I - Sum of Gaussian peaks & $I=\sum_{1}^{n} A_{n} e^{\left[\frac{-\left(v-v_{0, n}\right)^{2}}{s_{n}^{2}}\right]}$ \\
\hline $\begin{array}{l}\text { Model II - Sum of peaks represented by a product of Gaussian and Lorentzian } \\
\text { peak with equal peak width }\end{array}$ & $I=\sum_{1}^{n} B_{n} e^{\left[\frac{-\left(v-v_{0, n}\right)^{2}}{s_{n}^{2}}\right]}\left[1+\frac{\left(v-v_{0, n}\right)^{2}}{s_{n}^{2}}\right]^{-1}$ \\
\hline $\begin{array}{l}\text { Model III - Sum of peaks represented by a product of Gaussian and Lorentzian } \\
\text { peak with different peak width }\end{array}$ & $I=\sum_{1}^{n} B_{n} e^{\left[\frac{-\left(v-v_{0, n}\right)^{2}}{s_{n}^{2}}\right]}\left[1+\frac{\left(v-v_{0, n}\right)^{2}}{\left(s_{n}^{\prime}\right)^{2}}\right]^{-1}$ \\
\hline Model IV - Sum of Lorentzian peaks & $I=\sum_{1}^{n} A_{n}\left[1+\frac{\left(v-v_{0, n}\right)^{2}}{s^{2}}\right]^{-1}$ \\
\hline
\end{tabular}


Model III can assume a variety of shapes, depending on the relative value of the peak widths. If the same value of bandwidth s of the other models is used in the Gaussian part of Model III, a larger value for s', the bandwidth term of the Lorentzian part, results in a wider peak (Model III (a)) as compared to Model I. A smaller value for s' results in a narrower peak (Modell III (b)). By proper selection of $s$ and s' values one can change from a Gaussian like peak shape to a Lorentzian one.

Curve fitting was carried out with the CurveExpert software (available at http://curveexpert.webhop.net/). The goodness-of-fit of the fitted curve and the derivative curves was estimated by the DIS parameter. The analysis was concluded with the comparison of the resolved peaks with those expected from theory, as summarized in Figure 1 and Figure 2.

\section{Results}

For the sake of simplification, the curve fitting of the unaged optical fiber only will be given in full detail, with the presentation of the results for all models of Table 1. For the other ageing conditions, only the model with the best goodness-of-fit will be discussed.

\section{Spectrum 1: unaged fiber}

Figure 5a shows the background corrected and smoothed experimental spectrum. Due to the highly overlapped peaks, no single peak or band could be distinguished. Above $3800 \mathrm{~cm}^{-1}$, the spectrum showed no relevant feature and this part of the spectrum was not considered during further analysis. Superimposed on the spectrum is the graph of the second derivative, which exposed the presence of four peaks at 3640, 3450, 3300 and $3120 \mathrm{~cm}^{-1}$. Higher order derivatives revealed no additional overlapped or hidden peak, as shown by the graph of the fourth derivative of Figure 5b. A resolution enhanced spectrum could thus be obtained through equation (2) using the second derivative with an appropriate $\mathrm{k}_{2}$ value (Figure $5 \mathrm{c}$ ), from which initial guesses of the peak maximum $v_{0}$, peak height $\mathrm{A}$ and peak width s for curve fitting were estimated.

The main findings of curve fitting can be summarized as follows: The different models revealed the same resolved peak pattern, with peaks around 3630, 3475, 3300 and $3125 \mathrm{~cm}^{-1}$ (Figure 6). However, differences were observed for peak maximum, peak height and peak width (Table 2). The differences for the peak width are understandable, since this parameter is linked to the peak shape. However, it is worth to note that Model III yields two peak width parameters, whose values differ markedly. Since the values
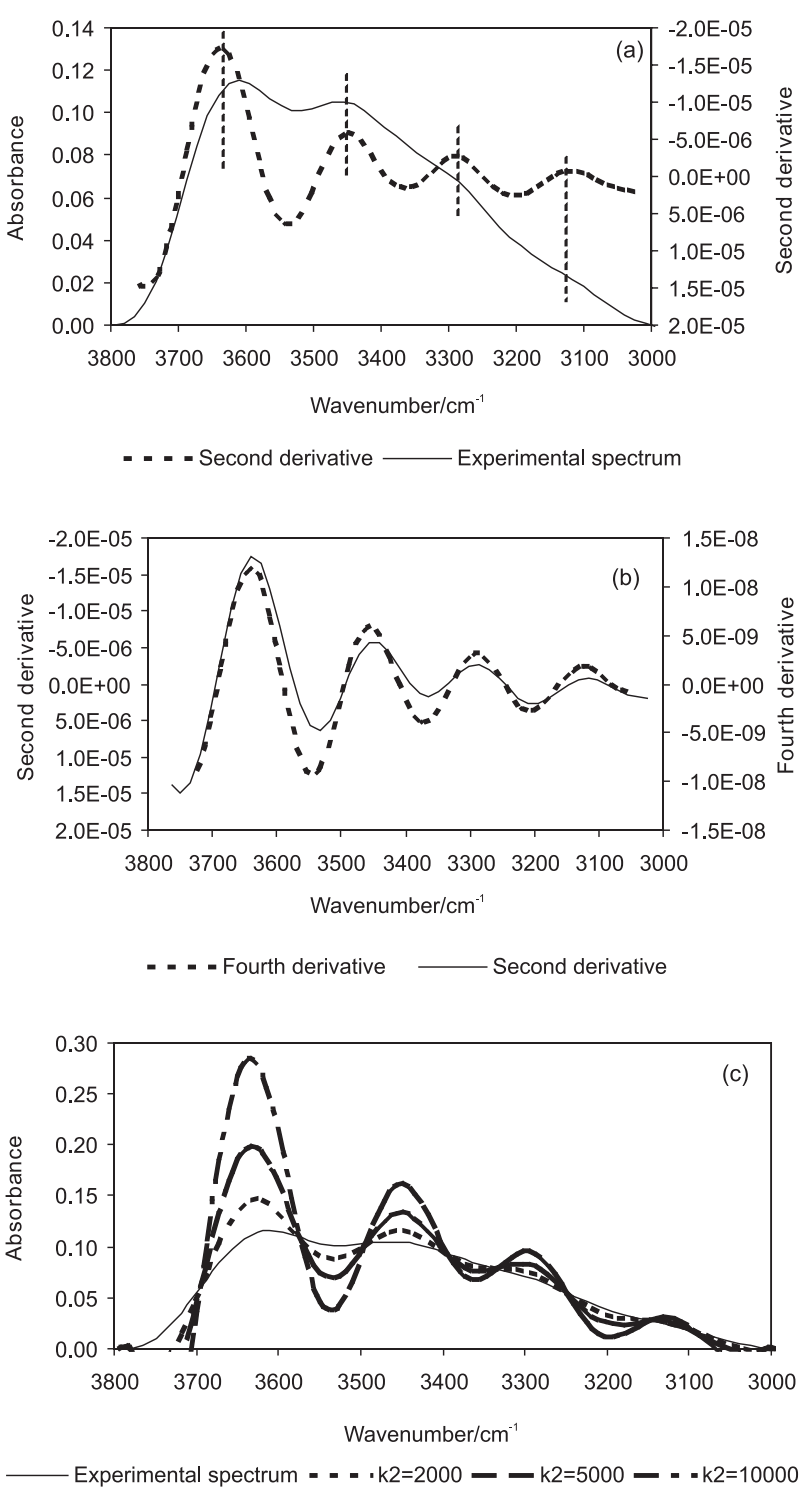

Figure 5. Resolution enhancement of experimental spectrum. (a) Experimental spectrum; (b) Analysis of derivatives and (c) Resolution enhanced spectrum

for $\mathrm{s}$, the peak shape parameter of the Gaussian part in the model equation, were closer to the peak width values of the other models, it is assumed that $\mathrm{s}$ is more representative of the peak width, whereas the role of s' is that of a fitting parameter.

Attempts to curve fit with Model IV and to include the peak at $3125 \mathrm{~cm}^{-1}$ proved unsuccessful. As can be seen in Figure 6d, due to the wide base of the Lorentzian peak, at $3125 \mathrm{~cm}^{-1}$ the total absorbance was made up of the contribution of the three major peaks at 3630,3475 and $3300 \mathrm{~cm}^{-1}$. It therefore became difficult for the curve fitting program to single out a separate peak at $3125 \mathrm{~cm}^{-1}$.

Table 3 presents the different models in ascending order of the goodness-of-fit parameters. The best fit was 


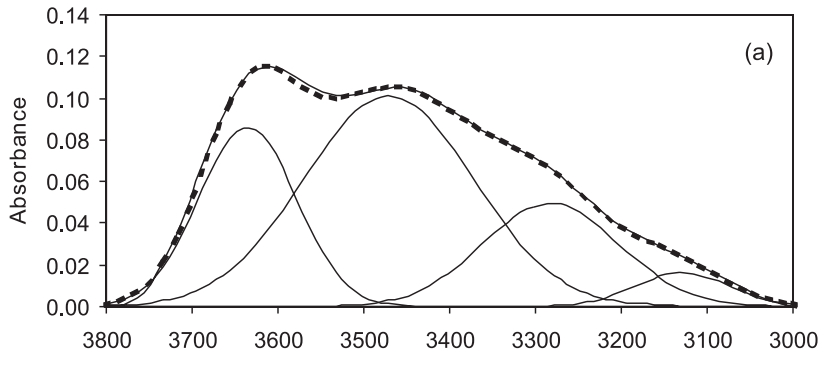

Wavenumber/cm

_ Experimental spectrum and individual peaks - - - . Fitted curve

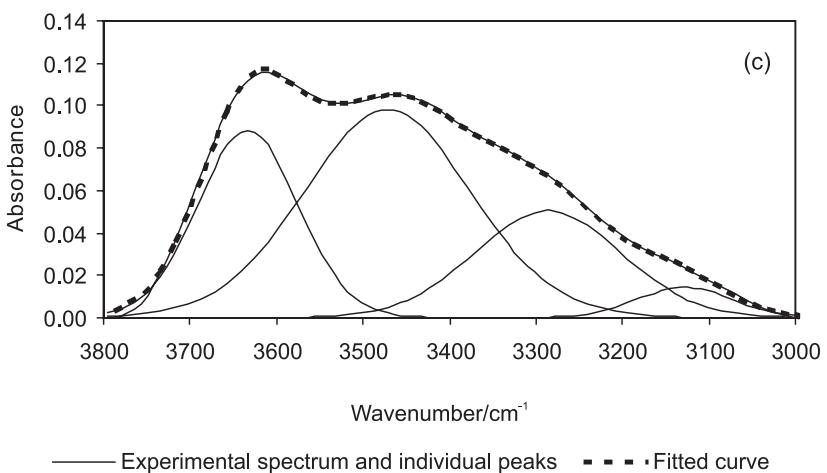

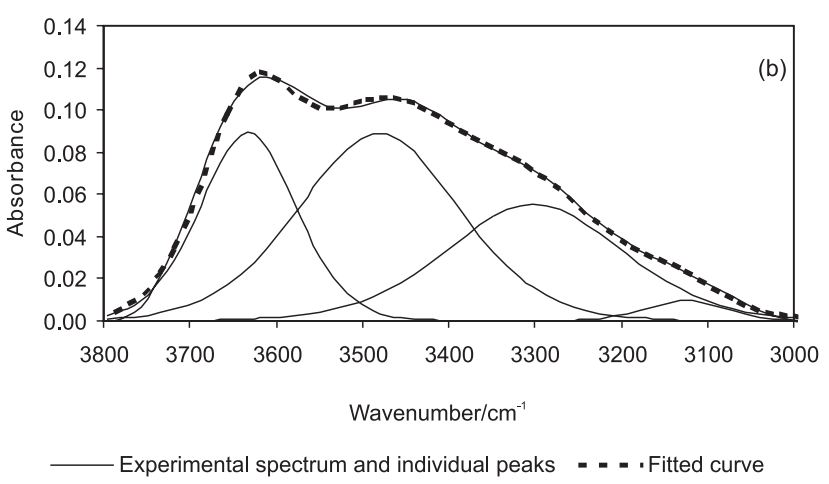

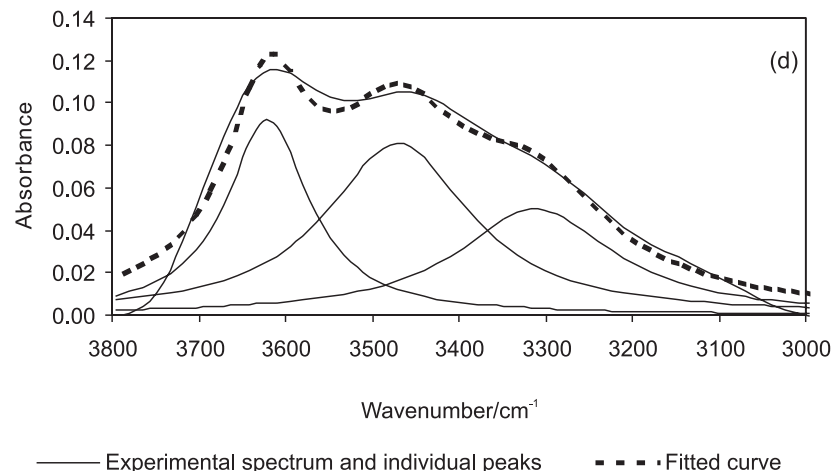

Figure 6. Curve fitting according to the different models. (a) Model I; (b) Model II; (c) Model III and (d) Model IV.

Table 2. Numerical results of curve fitting

\begin{tabular}{lccccc}
\hline $\begin{array}{l}\text { Initial guess } \\
\text { for peak } \\
\text { maximum }\end{array}$ & Parameter & $\begin{array}{c}\text { Model } \\
\text { I }\end{array}$ & $\begin{array}{c}\text { Model } \\
\text { II }\end{array}$ & $\begin{array}{c}\text { Model } \\
\text { III }\end{array}$ & $\begin{array}{c}\text { Model } \\
\text { IV }\end{array}$ \\
\hline $3640 \mathrm{~cm}^{-1}$ & $v_{0}$ & 3635.46 & 3632.36 & 3633.05 & 3620.34 \\
& A & 0.0863 & 0.0891 & 0.0885 & 0.0918 \\
& s & 79.81 & 107.02 & 92.20 & 58.74 \\
$3450 \mathrm{~cm}^{-1}$ & s & - & - & 165.86 & - \\
& $v_{0}$ & 3475.96 & 3480.75 & 3471.69 & 3470.27 \\
& A & 0.0992 & 0.0889 & 0.0982 & 0.0808 \\
$3300 \mathrm{~cm}^{-1}$ & s & 138.00 & 178.21 & 160.00 & 101.10 \\
& s' & - & - & 246.50 & - \\
& A & 3284.95 & 3300.35 & 3286.06 & 3311.60 \\
& s & 0.0520 & 0.0554 & 0.0506 & 0.0500 \\
$3120 \mathrm{~cm}^{-1}$ & s' & - & - & 217.85 & - \\
& v & 3122.90 & 3125.25 & 3127.60 & - \\
& A & 0.0140 & 0.0096 & 0.0144 & - \\
& s & 74.40 & 88.14 & 92.20 & - \\
& s' & - & - & 134.59 & - \\
\hline
\end{tabular}

anit $\left(\mathrm{cm}^{-1}\right), v_{0}$ - peak maximum, s - peak width and s' - the bandwidth term of the Lorentzian part, except A. A - peak height.
Table 3. Goodness-of-fit analysis - DIS values

\begin{tabular}{lccc}
\hline Model & Fitted curve & Second derivative & Fourth derivative \\
\hline I & $1.25 \times 10^{-3}$ & $1.58 \times 10^{-6}$ & $2.66 \times 10^{-9}$ \\
III & $1.38 \times 10^{-3}$ & $1.72 \times 10^{-6}$ & $2.85 \times 10^{-9}$ \\
II & $1.91 \times 10^{-3}$ & $2.67 \times 10^{-6}$ & $4.97 \times 10^{-9}$ \\
IV & $7.27 \times 10^{-3}$ & $7.41 \times 10^{-6}$ & $1.57 \times 10^{-8}$ \\
\hline
\end{tabular}

reached with pure Gaussian peak shapes (Model I), which showed the lowest DIS parameter. The worst fit was with Lorentzian peaks (Model IV). This was true not only for the curve fitted spectrum curve, but also for the derivative curves. Moreover, in the composite models (Model II and III), the Gaussian character was predominant in the overall peak shape, as seen in Figure 6b and 6c.

The peak maxima at 3300 and $3125 \mathrm{~cm}^{-1}$ matched closely the predicted ones from the second derivative curves of the experimental spectrum (Figure 5) and were assigned to the stretching vibrations of free molecular water of Figure 1 (3200-3250 $\mathrm{cm}^{-1}$ and $3140 \mathrm{~cm}^{-1}$, respectively). The peak at $3475 \mathrm{~cm}^{-1}$ is equivalent to the peak at $3450 \mathrm{~cm}^{-1}$ of the derivative curve and was assigned to stretching vibrations of adsorbed molecular water $3400-3450 \mathrm{~cm}^{-1}$ in Figure 1. It is believed that for this peak the shift in peak maximum is a 
result of the curve fitting algorithm. The peak at $3630 \mathrm{~cm}^{-1}$ again matched close the equivalent peak of the derivative curve. It is halfway between the peak ranges of 3595$3625 \mathrm{~cm}^{-1}$ and $3660-3670 \mathrm{~cm}^{-1}$ of Figure 2 and may be in fact an envelope comprising both peaks. To investigate this hypothesis further, an additional curve fitting was carried out. Using Model I, the peak at $3630 \mathrm{~cm}^{-1}$ was replaced by two peaks with initial guesses at 3610 and $3670 \mathrm{~cm}^{-1}$ and appropriate guesses for peak height and peak width. The result of this curve fit is shown in Figure 7 and in Tables 4 and 5. It can be seen that the peak at $3630 \mathrm{~cm}^{-1}$ can be conveniently substituted by two peaks at 3612 and $3675 \mathrm{~cm}^{-1}$, thus bringing the model closer to theoretical predictions, since they fall within the $3595-3625 \mathrm{~cm}^{-1}$ and $3660-3670 \mathrm{~cm}^{-1}$ peak ranges of Figure 2. Furthermore, the

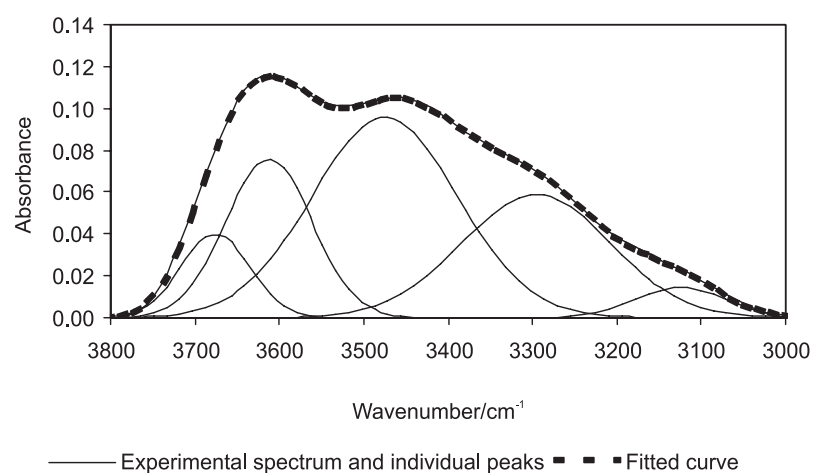

Figure 7. Curve fitting with modified Model I.

Table 4. Numerical results of curve fitting with modified Model I

\begin{tabular}{lcc}
\hline Initial guess for peak maximum & Parameter $^{\mathrm{a}}$ & Model I modified \\
\hline $3670 \mathrm{~cm}^{-1}$ & $v_{0}$ & 3675.50 \\
& A & 0.0399 \\
$3610 \mathrm{~cm}^{-1}$ & $\mathrm{~s}$ & 58.39 \\
& $v_{0}$ & 3612.15 \\
& A & 0.0759 \\
$3475 \mathrm{~cm}^{-1}$ & $\mathrm{~s}$ & 72.15 \\
& $v_{0}$ & 3475.96 \\
$3300 \mathrm{~cm}^{-1}$ & A & 0.0992 \\
& $\mathrm{~s}$ & 138.00 \\
$3125 \mathrm{~cm}^{-1}$ & $v_{0}$ & 3284.95 \\
& A & 0.0520 \\
& s & 121.81 \\
& v & 3122.90 \\
& A & 0.0140 \\
\hline
\end{tabular}

$\overline{{ }^{a} \text { Unit }\left(\mathrm{cm}^{-1}\right), v_{0} \text { - peak maximum and } \mathrm{s} \text { - peak width, except A. A - peak }}$ height.
Table 5. Goodness-of-fit analysis for modified Model I - DIS values

\begin{tabular}{lcc}
\hline Fitted curve & Second derivative & Fourth derivative \\
\hline $5.15 \times 10^{-4}$ & $9.74 \times 10^{-7}$ & $2.51 \times 10^{-9}$ \\
\hline
\end{tabular}

splitting up of the $3630 \mathrm{~cm}^{-1}$ peak into two peaks improved the goodness-of-fit at all levels.

The analysis of this spectrum and its resolved peaks - three below $3500 \mathrm{~cm}^{-1}$ and two above - indicated that the glass surface of the unaged fiber contained significant amount of both unbounded molecular water and dissolved water (bounded water) in the silica structure.

\section{Spectrum 2: field aged fiber}

Figure 8a shows the background corrected and smoothed experimental spectrum. Similar to the previous case, no single peak could be distinguished due to overlapping peaks and no relevant feature was present above $3800 \mathrm{~cm}^{-1}$. Compared to the previous case, the peak around $3450 \mathrm{~cm}^{-1}$ is more pronounced. The superimposed graph of the second derivative, however, revealed, besides the existence of three well defined peaks at around 3640, 3450 and $3200 \mathrm{~cm}^{-1}$, the presence of a barely visible peak around $3340 \mathrm{~cm}^{-1}$. To unveil this peak, it was necessary to further derivate so as to increase the slope differences in the graph, shown in Figure $8 \mathrm{~b}$. This time the resolution enhanced spectrum was obtained through equation (2) using the fourth derivative.

Curve fitting followed as described for the unaged condition and the main results were as follows: The curve fitted peak maxima matched closely the predicted ones from the derivative curves for all models. The predicted peaks at $3640,3450,3340$ and $3200 \mathrm{~cm}^{-1}$ varied with curve fitting in the range of $3619-3640 \mathrm{~cm}^{-1}, 3453-3468 \mathrm{~cm}^{-1}$, $3320-3353 \mathrm{~cm}^{-1}$ and $3210-3242 \mathrm{~cm}^{-1}$, respectively.

While the $3450 \mathrm{~cm}^{-1}$ is related to adsorbed molecular water and the $3200 \mathrm{~cm}^{-1}$ peak to free molecular water, the peak at $3340 \mathrm{~cm}^{-1}$ is a distinctive peak halfway between both. Although this peak is not related to any type of silicawater interaction described in Figure 1, it is believed that it can be traced to molecular water in silica, too. ${ }^{19}$

However, this time the goodness-of-fit analysis had to proceed more carefully in order to pick up the most suitable model. Table 6 shows that, from Model I to IV, while the goodness-of-fit of the fitted curve was best for Model I, for the second derivative it was best for Model II and for the fourth derivative it was for Model III. The modified Model I, in which the peak at $3640 \mathrm{~cm}^{-1}$ is replaced by two peaks with initial guesses at 3610 and $3670 \mathrm{~cm}^{-1}$, improved the goodness-of-fit in relation to the other models, except for the fourth derivative curve. However, since the goodness-of- 
fit for the fourth derivative curves of both modified Model I and Model III have the same order of magnitude and are close in value, it was decided to choose the former over the last model. Here again, the splitting of the $3640 \mathrm{~cm}^{-1}$ peak in two smaller peaks at 3622 and $3680 \mathrm{~cm}^{-1}$ (Table 7 and Figure 9) brought the model closer to theoretical predictions.

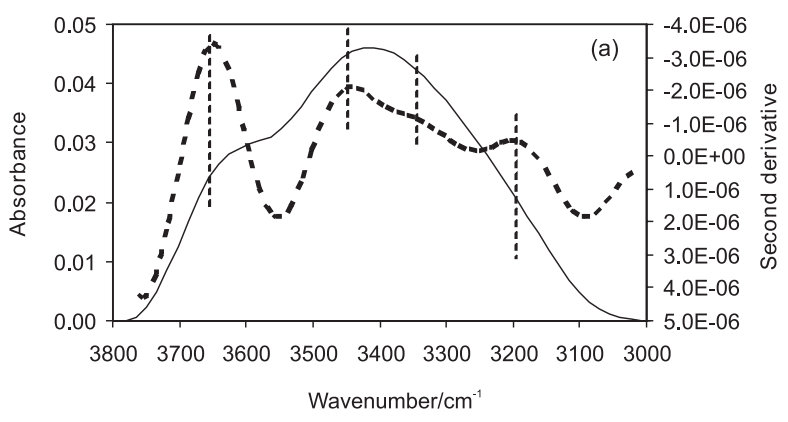

- - - - Second derivative _— Experimental spectrum

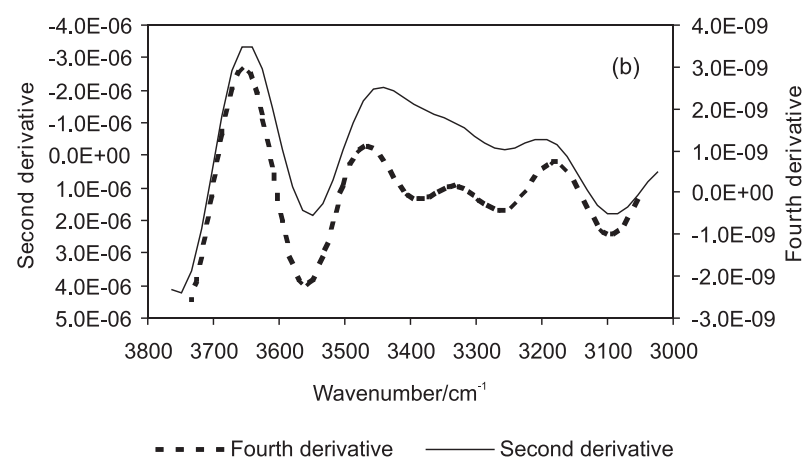

Figure 8. Resolution enhancement of experimental spectrum. (a) Experimental spectrum and (b) Analysis of derivatives.

Table 6. Goodness-of-fit analysis - DIS values

\begin{tabular}{lccc}
\hline Model & Fitted curve & Second derivative & Fourth derivative \\
\hline I & $3.75 \times 10^{-4}$ & $5.51 \times 10^{-6}$ & $5.06 \times 10^{-9}$ \\
II & $6.09 \times 10^{-4}$ & $5.31 \times 10^{-6}$ & $3.94 \times 10^{-9}$ \\
III & $4.94 \times 10^{-4}$ & $5.32 \times 10^{-6}$ & $3.90 \times 10^{-9}$ \\
IV & $2.47 \times 10^{-3}$ & $6.80 \times 10^{-6}$ & $5.68 \times 10^{-9}$ \\
Modified I & $1.54 \times 10^{-4}$ & $5.25 \times 10^{-6}$ & $3.99 \times 10^{-9}$ \\
\hline
\end{tabular}

The resolved spectrum with its predominant peak at $3457.25 \mathrm{~cm}^{-1}$ showed that the environmental conditions during field exposure (e.g. exposure to high humidity or aqueous environment) had led to water absorption by the silica surface of the optical fiber, despite the protective polymer coating. ${ }^{25}$ The absorbed water entered the silica structure as unbounded molecular water. However, under
Table 7. Numerical results of curve fitting with modified Model I

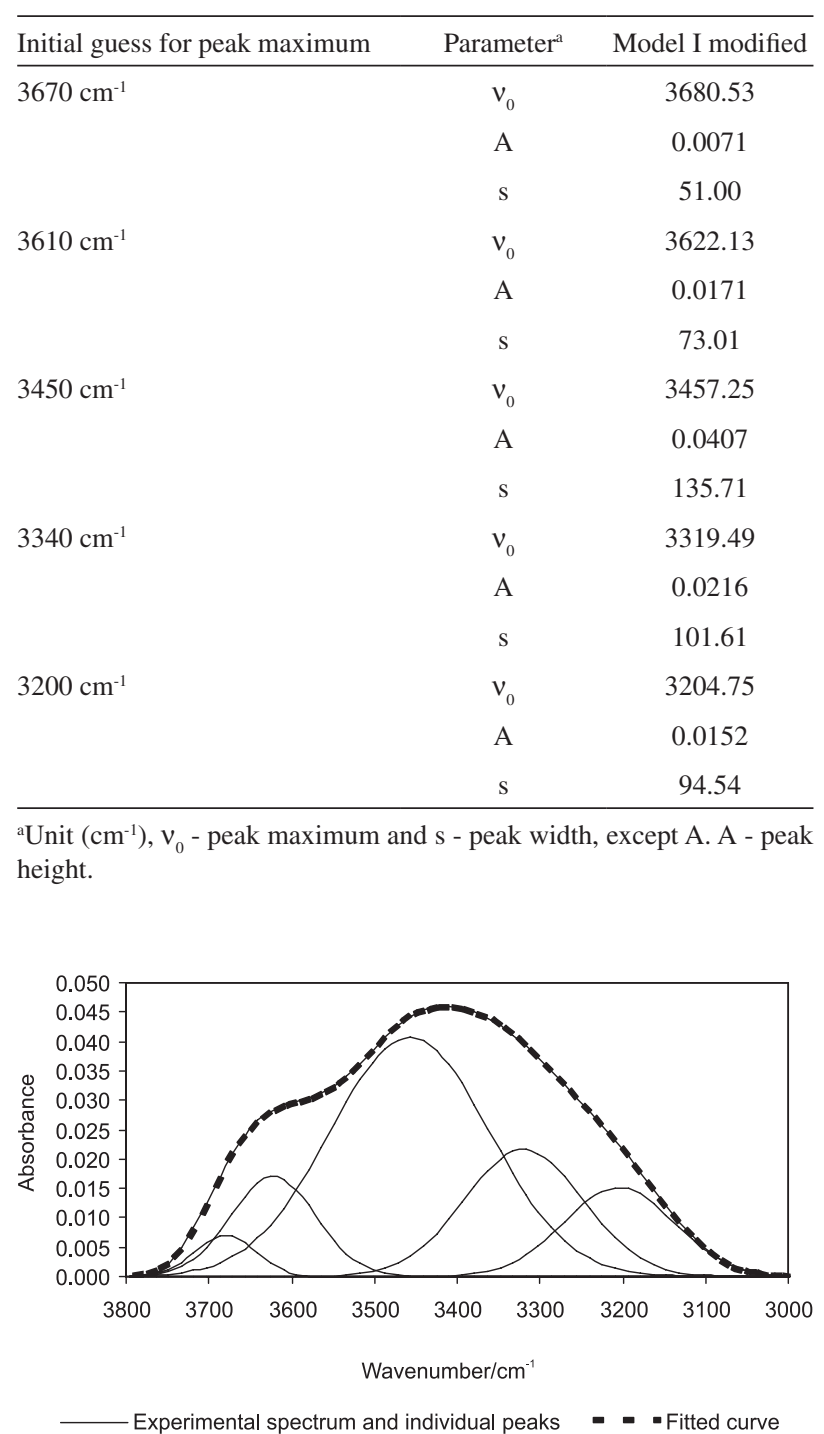

Figure 9. Curve fitting with modified Model I.

the prevailing field ageing conditions, the water did show little tendency to react with silica to form bounded water in the form of hydroxyls, despite the long ageing time.

Spectrum 3: 14 days ageing at room temperature and under compressive stress of $0.5 \mathrm{GPa}$

Figure 10a shows the background corrected and smoothed experimental spectrum. Unlike the other cases, this spectrum showed prominent peaks above $3500 \mathrm{~cm}^{-1}$, namely at around 3640 and $3900 \mathrm{~cm}^{-1}$. Peaks lower than $3500 \mathrm{~cm}^{-1}$ were hardly distinguishable due to strong overlap. The analysis of the graph of the second derivative, however, disclosed the presence of three peaks at 3400, 3250 and $3080 \mathrm{~cm}^{-1}$. Moreover, the graph of the fourth derivative of 


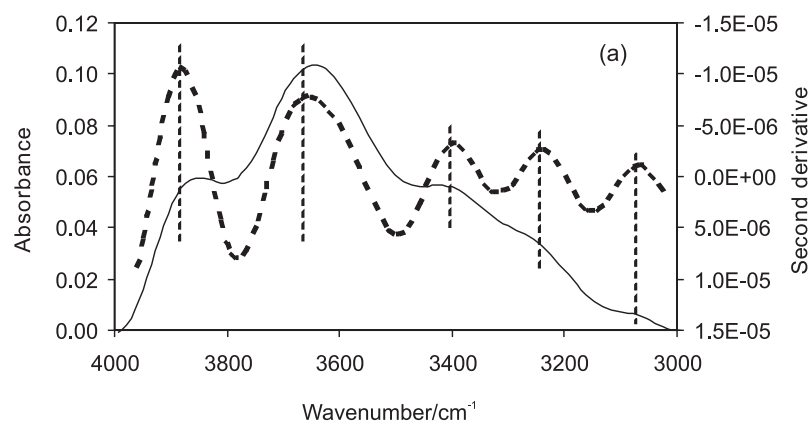

- - - Second derivative _-Experimental spectrum

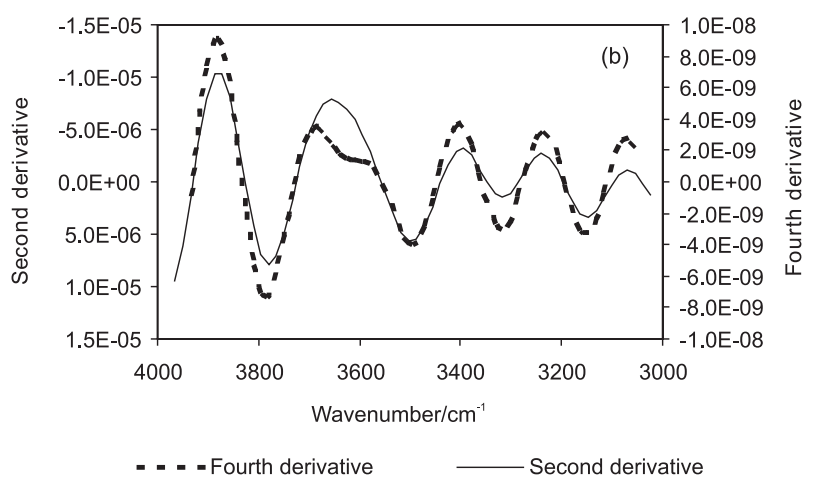

Figure 10. Resolution enhancement of experimental spectrum. (a) Experimental spectrum and (b) Analysis of derivatives.

Figure 10b revealed under the envelop of $3640 \mathrm{~cm}^{-1}$ two hidden peaks, with strong overlapping. The peak maxima were estimated to be around 3700 and $3600 \mathrm{~cm}^{-1}$.

Curve fitting showed that the fitted peak maxima matched closely the predicted ones from the derivative curves for all models. The predicted peaks at 3080, 3250, 3400, 3600, 3700 and $3900 \mathrm{~cm}^{-1}$ varied with curve fitting in the range

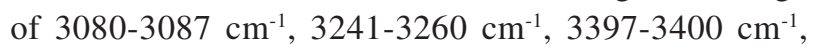
$3580-3600 \mathrm{~cm}^{-1}, 3660-3700 \mathrm{~cm}^{-1}$ and $3860-3900 \mathrm{~cm}^{-1}$, respectively. The best fit was again for Model I, with pure Gaussian peaks (Table 8, Table 9 and Figure 11).

From Figure 1 it follows that the peaks at 3080, 3250 and $3400 \mathrm{~cm}^{-1}$ are due to free and adsorbed molecular water, whereas the ones at 3600 and $3700 \mathrm{~cm}^{-1}$ are due to dissolved water. The peak at $3900 \mathrm{~cm}^{-1}$ is ascribed to a combination of various $\equiv \mathrm{Si}-\mathrm{OH}$ vibration modes. ${ }^{2,26}$

In contrast to the previouscases, where the peak at $3640 \mathrm{~cm}^{-1}$ was artificially replaced by two smaller based on prior knowledge of the system under investigation, in the present case the two peaks at 3600 and $3700 \mathrm{~cm}^{-1}$ showed up in the derivative curves which were assigned to the 3595$3625 \mathrm{~cm}^{-1}$ and $3660-3670 \mathrm{~cm}^{-1}$ peak ranges of Figure 1.

Due to the same reason mentioned for Spectrum 1, curve fitting with pure Lorentzian peaks was successful only by excluding the small peak at $3080 \mathrm{~cm}^{-1}$.
Table 8. Goodness-of-fit analysis - DIS values

\begin{tabular}{lccc}
\hline Model & Fitted curve & Second derivative & Fourth derivative \\
\hline I & $8.72 \times 10^{-4}$ & $1.16 \times 10^{-6}$ & $2.36 \times 10^{-9}$ \\
II & $1.11 \times 10^{-3}$ & $1.27 \times 10^{-6}$ & $2.71 \times 10^{-9}$ \\
III & $1.20 \times 10^{-3}$ & $1.53 \times 10^{-6}$ & $3.34 \times 10^{-9}$ \\
IV & $3.69 \times 10^{-3}$ & $4.69 \times 10^{-6}$ & $4.37 \times 10^{-9}$ \\
\hline
\end{tabular}

Table 9. Numerical results of curve fitting with Model I

\begin{tabular}{lcc}
\hline Initial guess for peak maximum & Parameter & Model I modified \\
\hline $3900 \mathrm{~cm}^{-1}$ & $v_{0}$ & 3872.51 \\
& A & 0.0456 \\
$3700 \mathrm{~cm}^{-1}$ & $\mathrm{~s}$ & 70.24 \\
& $v_{0}$ & 3694.04 \\
& A & 0.0710 \\
$3600 \mathrm{~cm}^{-1}$ & $\mathrm{~s}$ & 136.61 \\
& $v_{0}$ & 3591.25 \\
$3400 \mathrm{~cm}^{-1}$ & A & 0.0500 \\
& $\mathrm{~s}$ & 114.34 \\
$3250 \mathrm{~cm}^{-1}$ & $v_{0}$ & 3400.91 \\
& A & 0.0505 \\
$3080 \mathrm{~cm}^{-1}$ & $\mathrm{~s}$ & 115.74 \\
& $v_{0}$ & 3241.20 \\
& A & 0.0257 \\
& $\mathrm{~s}$ & 91.96 \\
& $v_{0}$ & 3087.60 \\
& A & 0.0053 \\
& $\mathrm{~s}$ & 55.67 \\
\hline
\end{tabular}

${ }^{\mathrm{a} U n i t}\left(\mathrm{~cm}^{-1}\right), v_{0}$ - peak maximum and $\mathrm{s}$ - peak width, except A. A - peak height.

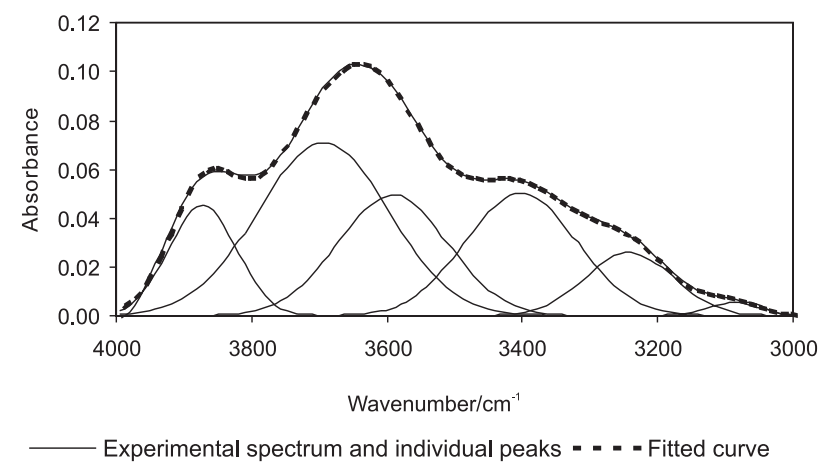

Figure 11. Curve fitting with Model I.

The strong presence of peaks associated with bounded water, $3872.51,3694.04$ and $3591.25 \mathrm{~cm}^{-1}$, indicates that exposure of hydrolyzed silica to compressive stress increased water dissolution into the silica structure as 
hydroxyl, as expected by theory. ${ }^{27}$ Dissolution of water in silica occurs by the following reaction:

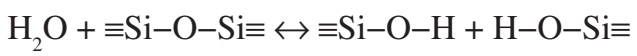

For this reaction to occur, the water molecules have to diffuse into the silica structure to reach propitious reaction sites, e.g., non bridging oxygen atoms, dangling bonds or low angle hydrophilic $\equiv \mathrm{Si}-\mathrm{O}-\mathrm{Si} \equiv$ bonds. ${ }^{28}$ Tensile stress favors water diffusion, whereas compressive stress favors dissolution reaction. ${ }^{27}$

\section{Discussion}

For all cases investigated, the combination of the analysis of derivatives with the knowledge of theoretical aspects of the system was important to fully resolve a highly overlapped spectrum. A further aspect to substantiate the analysis carried out herein follows from the application of the peak separation criterion to each pair of overlapping peaks. This will be shown in detail for Spectrum 3, but is easily extended to the other cases.

As stated above, the visual separation of two overlapping peaks by a valley or plateau defines the shoulder limit and is expressed mathematically by equation $8 .{ }^{17}$ The graphic representation of this expression is shown in Figure 12 for Spectrum 3. At $3456 \mathrm{~cm}^{-1}$, between the peaks at 3640

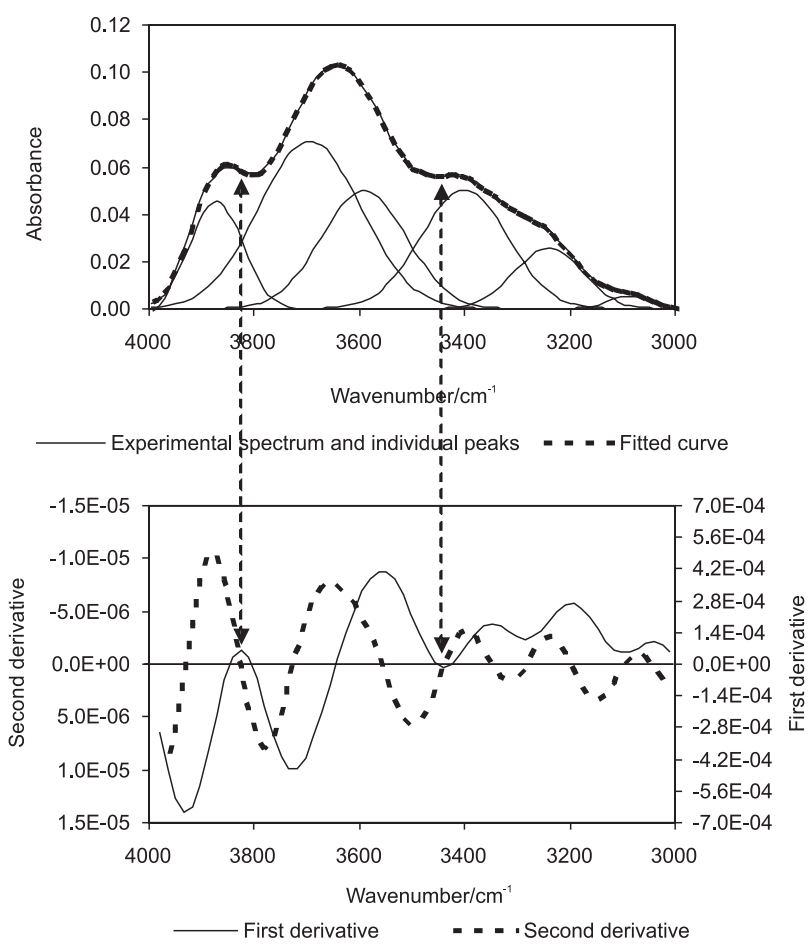

Figure 12. The shoulder limit. Top: Location in the spectrum. Bottom: Graphical representation. and $3400 \mathrm{~cm}^{-1}$, equation 8 is exactly zero and the spectrum exhibits a valley at the limit of visual perception. If the peak distance gets shorter, the valley would gradually disappear, the minor peak maximum would become less distinctive from the major peak and equation 8 would shift from zero. If the distance gets longer, the valley and the individual peaks would become more discernible and equation 8 would shift from zero again. This last situation is depicted at $3826 \mathrm{~cm}^{-1}$, between the peaks at 3900 and $3640 \mathrm{~cm}^{-1}$. All other pairs of overlapping peaks are poorly resolved in the original spectrum and equation 8 is far from zero.

Vandengist and De Galan ${ }^{18}$ solved equation 8 and presented the solution in graphical form which shows the shoulder limit of two overlapping peaks for various ratios of peak height $\left(\mathrm{R}=\mathrm{A}_{2} / \mathrm{A}_{1}\right)$, peak width $\left(\varphi=\mathrm{s}_{2} / \mathrm{s}_{1}\right)$ and peak distance $\left(\delta=\left[v_{2}-v_{1}\right] \cdot\left[\left(s_{2}\right)^{-1}+\left(s_{1}\right)^{-1}\right]\right)$. Figure 13 shows selected curves which were retrieved from Figure 1 of the paper of Vandengist and De Galan, which represents graphically the shoulder limit for two overlapping Gaussian peaks. ${ }^{18}$ The curves are those with values of $\mathrm{R}, \varphi$ and $\delta$ closest to the ones of the overlapping peaks of Spectrum 3. The overlapping peaks were placed in Figure 13 using the values of Table 10 which, in turn, were calculated using the values of Table 9. Two overlapping peaks are beyond the shoulder limit and can be visually distinguished if the symbol representing this pair of peaks is above and to the right of the curve with equal $\varphi$ value. Below and to the left, they are under the shoulder limit and cannot be distinguished. For the sake of clarity, a single graph was drawn for each pair of overlapping peak with its respective curves. Hence, in Figure 13a and 13c, the peak at $3872.51 \mathrm{~cm}^{-1}$ can be distinguished from the one at $3694.04 \mathrm{~cm}^{-1}$ and the peak at $3591.25 \mathrm{~cm}^{-1}$ from that at $3400.91 \mathrm{~cm}^{-1}$, respectively. However, since the peak at $3694.04 \mathrm{~cm}^{-1}$ cannot be distinguished from the peak at $3591.25 \mathrm{~cm}^{-1}$ (Figure 13b), one sees in the experimental spectrum only an envelope comprising both peaks at $3640 \mathrm{~cm}^{-1}$. This larger peak, on one side, is exactly at the shoulder limit with the peak at $3400 \mathrm{~cm}^{-1}$, since it lies in Figure $13 \mathrm{f}$ almost on the curve of $\varphi=1.7$ (between $\varphi=1.6$ and $\varphi=1.8$ ), which is the same value of $\varphi$ for the $3640 / 3400 \mathrm{~cm}^{-1}$ pair of overlapping peaks (Table 10). On the other side, the $3640 \mathrm{~cm}^{-1}$ peak is beyond the shoulder limit with the one at $3872 \mathrm{~cm}^{-1}$ (Note: To calculate the values for $\mathrm{R}, \varphi$ and $\delta$ for the pair of overlapping peaks $3872 / 3640 \mathrm{~cm}^{-1}$ and $3640 / 3400 \mathrm{~cm}^{-1}$, curve fitting with Model I was repeated replacing the peaks at 3700 and $3600 \mathrm{~cm}^{-1}$ by a single peak at $3640 \mathrm{~cm}^{-1}$ ). Due to strong overlapping, the pairs of peaks at $3400.91 / 3241.20 \mathrm{~cm}^{-1}$ and at $3241.20 / 3087.60 \mathrm{~cm}^{-1}$ are under the shoulder limit. Therefore, they cannot be visually distinguished in the experimental spectrum (Figure 13d and 13e). 

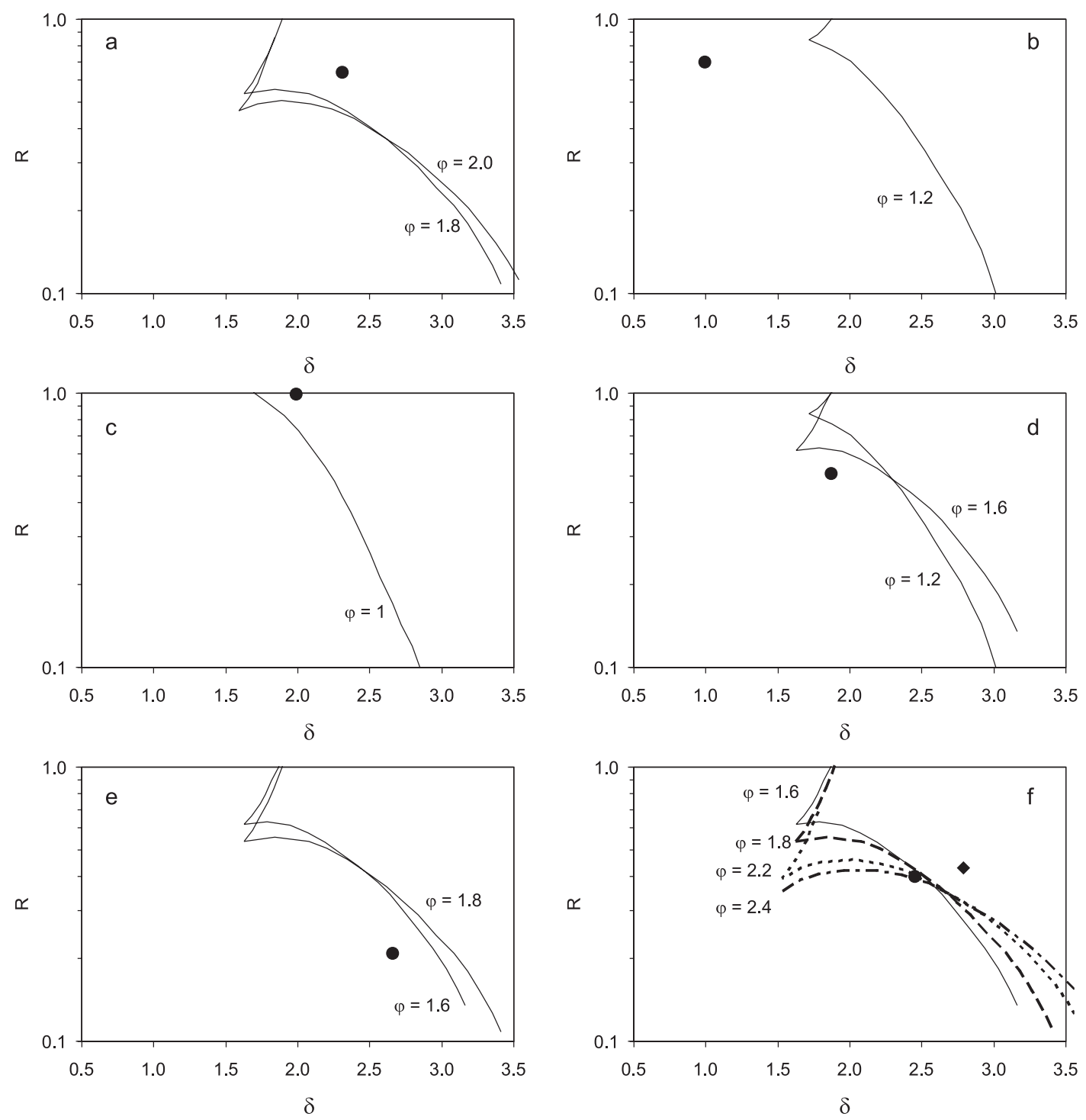

Figure 13. Graphical representation of the shoulder limit (curves) and location of the overlapping peaks of Spectrum 3 (symbols). (a) $3872.51 / 3694.04 \mathrm{~cm}^{-1}$; (b) $3694.04 / 3591.25 \mathrm{~cm}^{-1}$; (c) $3591.25 / 3400.91 \mathrm{~cm}^{-1}$; (d) $3400.91 / 3241.20 \mathrm{~cm}^{-1}$; (e) $3241.20 / 3087.60 \mathrm{~cm}^{-1}$ and (f) $3872 / 3640 \mathrm{~cm}^{-1}, 3640 / 3400 \mathrm{~cm}^{-1}$.

It follows from the foregoing that the shoulder limit map of Figure 13 is in close agreement with the spectral features of Figure 12. In fact, this map should be regarded as a validation tool for any peak separation procedure. It not only explains the experimental spectrum obtained, but it also supports the inclusion in curve fitting models of hidden spectral features which are justified from theory.

A similar approach can be adopted for the detection limit, which is defined by an inflection point in the spectrum that coincides with the maximum of the minor peak and is expressed mathematically by equation $9 .{ }^{17}$ This is represented graphically in Figure 14 for Spectrum 3. For instance, at $3100 \mathrm{~cm}^{-1}$, equation 9 is nearly fulfilled and the spectrum shows an inflection point (Figure 15) which is close to the peak maximum at $3087.60 \mathrm{~cm}^{-1}$ (Table 10).
Table 10. Values of R, $\varphi$ and $\delta$ for Spectrum 3, as calculated from the data of Table 9

\begin{tabular}{lccc}
\hline Overlapping peaks/ $\left(\mathrm{cm}^{-1}\right)$ & $\delta$ & $\mathrm{R}$ & $\varphi$ \\
\hline $3872.51 / 3694.04$ & 2.31 & 0.64 & 1.9 \\
$3694.04 / 3591.25$ & 0.99 & 0.70 & 1.2 \\
$3591.25 / 3400.91$ & 1.99 & 0.99 & 1.0 \\
$3400.91 / 3241.20$ & 1.87 & 0.51 & 1.3 \\
$3241.20 / 3087.60$ & 2.66 & 0.21 & 1.7 \\
\hline
\end{tabular}

Vandengist and De Galan solved equation 9 and presented the solution again in graphical form. ${ }^{18}$ Figure 16 is a concise form of Figure 3 of the paper of Vandengist and De Galan, again with selected curves whose values of $\mathrm{R}, \varphi$ and $\delta$ are closest to the ones of the overlapping peaks 


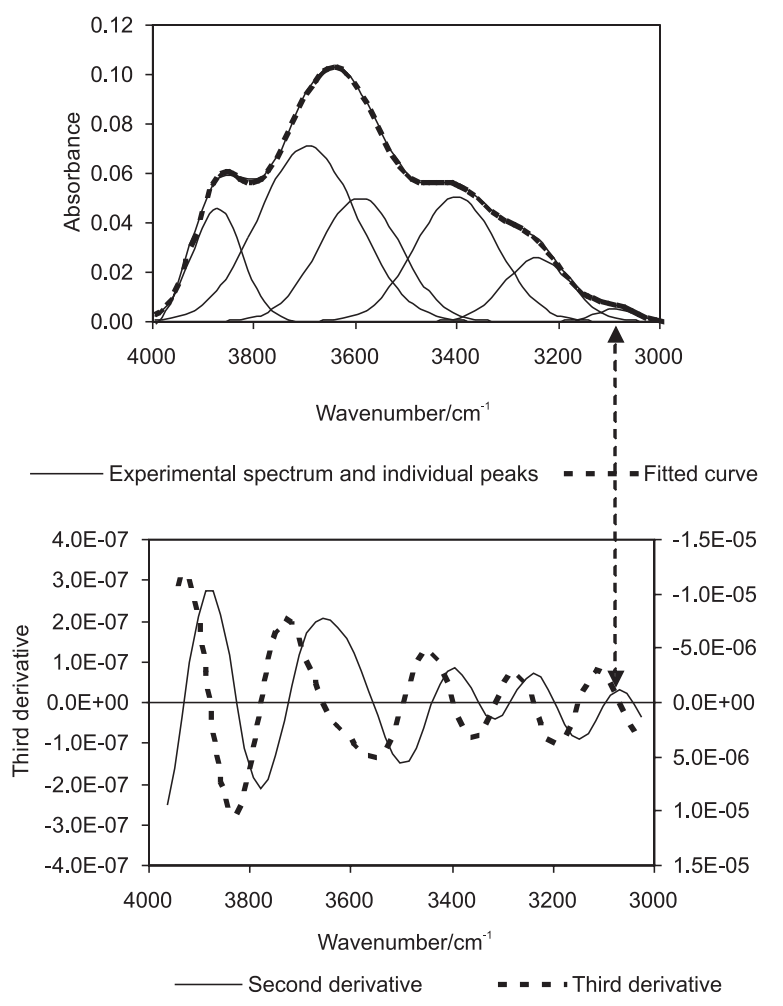

Figure 14. The detection limit. Top: Location in the spectrum. Bottom: Graphical representation.

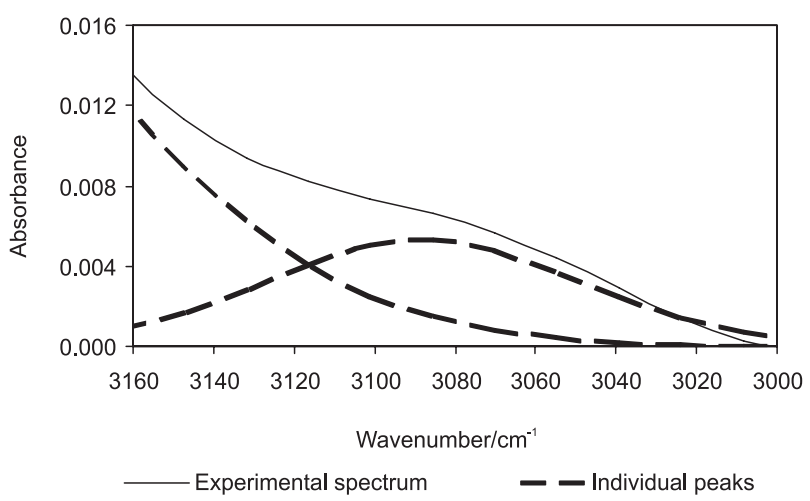

Figure 15. Magnification of the spectrum of Figure 14 at the low wavenumber side.

of Spectrum 3. This time, all pairs of overlapping peaks have been plotted in one single graph. To the right of the curves, two overlapping peaks are beyond the detection limit and should be detected with the aid of the second derivative, as was observed for most overlapping peaks of Spectrum 3. To the left, they are under the detection limit and cannot be detected by the second derivative alone. In this case, the presence of overlapped peaks may show up in the fourth derivative or has to be inferred from the previous knowledge about the investigated system. This was the case for the strongly overlapping peaks at

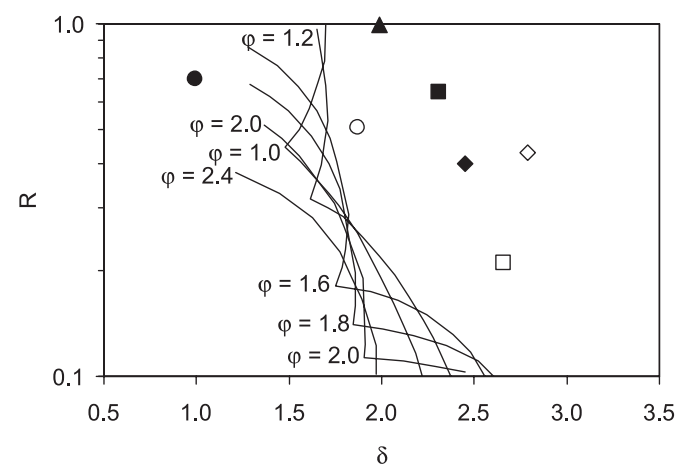

Figure 16. Graphical representation of the detection limit (curves) and location of the overlapping peaks of Spectrum 3 (filled and open points). - $3694.04 / 3591.25 \mathrm{~cm}^{-1} ; \bigcirc 3400.91 / 3241.20 \mathrm{~cm}^{-1}$; $3872.51 / 3694.04 \mathrm{~cm}^{-1}$; $\square 3241.20 / 3087.60 \mathrm{~cm}^{-1} ; \quad 3640 / 3400 \mathrm{~cm}^{-1} ; \diamond 3872 / 3640 \mathrm{~cm}^{-1}$ and \ $3591.25 / 3400.91 \mathrm{~cm}^{-1}$.

$3694.04 / 3591.25 \mathrm{~cm}^{-1}$, which were perceivable in the fourth derivative.

The above analysis is in agreement with Figure 10B. In fact, the detection limit map of Figure 16 is an additional tool to the shoulder limit map of Figure 13 to validate a peak separation procedure.

\section{Conclusions}

A procedure has been described for reliable peak separation of highly overlapped and hidden peaks in infrared spectra of hydrolyzed silica optical fibers in the 3000 and $4000 \mathrm{~cm}^{-1}$ range. The procedure allowed for the determination of the number and the locations of the peaks. Through the identified individual peaks it was possible to understand the silica-water interaction processes during ageing of a silica optical fiber. Several points emerged from the analyses that were common to the three examples investigated: (i) In the context of this study, curve fitting with pure Lorentzian peak shape did not prove reliable, since the characteristic wide base of the major peaks excluded the detection of an overlapped small peak and adversely affected the goodness-of-fit; (ii) The best goodness-of-fit, measured by the deviation (DIS) parameter, was obtained with a fitting model using pure Gaussian peak shapes. This was true not only for the fitted spectrum, but also for the second and fourth derivative curve; (iii) Even in the fitting models using compound peak shapes, described by a product of Gaussian and Lorentzian peak shapes, the Gaussian character was predominant in the overall peak shape; (iv) When the silica optical fibers contained more unbound molecular water than dissolved water, the peaks below $3500 \mathrm{~cm}^{-1}$ were predominant and the peak observed at $3630-3640 \mathrm{~cm}^{-1}$ could be described as an envelope comprising two smaller peaks in the ranges 
of $3595-3625 \mathrm{~cm}^{-1}$ and $3660-3670 \mathrm{~cm}^{-1}$. These two smaller peaks instead of one larger halfway between both were not evident in the experimental spectrum and its derivative curves, but were closer to theory, i.e., to what is known of the system under investigation. When the fibers contained more dissolved water, however, the peaks below $3500 \mathrm{~cm}^{-1}$ were hardly distinguishable and the peaks in the ranges of $3595-3625 \mathrm{~cm}^{-1}$ and $3660-3670 \mathrm{~cm}^{-1}$ became discernible in the fourth derivative curve; $(v)$ This study gave a practical example of the utility of the shoulder limit and detection limit maps developed by Vandengist and De Galan. ${ }^{18}$ They show the importance to consider hidden and overlapped peaks in a spectrum of the system under investigation that are under the detection limit. These peaks may not be detected even by the fourth derivate, yet their existence should not be excluded. Their inclusion in the fitting model may be justified from theory, i.e., from the existing knowledge of the system, and may improve the goodnessof-fit of the curve fitting.

\section{Supplementary Information}

Supplementary data are available free of charge at http:// jbcs.sbq.org.br, as PDF file.

\section{References}

1. Lórenz-Fonfría, V. A.; Padrós, E.; Appl. Spectrosc. 2005, 59, 474.

2. Davis, K. M.; Tomozawa, M.; J. Non-Cryst. Solids 1996, 201, 177.

3. Stone, J.; Walrafen, G. E.; J. Chem. Phys. 1982, 76, 1712.

4. http://www.lsbu.ac.uk/water/vibrat.html, accessed in April 2008.

5. ht t p ://www.wam.umd.edu/ toh/spectrum/ IntroToSignalProcessing.pdf, accessed in April 2008.

6. Brereton, R. G.; Chemometrics-Data Analysis for the Laboratory and Chemical Plant, John Wiley \& Sons: Chichester, 2004, 119.

7. Kauppinen, J. K.; Moffatt, D. J.; Mantsch, H. H.; Cameron, D. G.; Anal. Chem. 1981, 53, 1454.

8. Friesen, W. I.; Michaelian, K. H.; Appl. Spectrosc. 1985, 39, 484.

9. Friesen, W. I.; Michaelian, K. H.; Appl. Spectrosc. 1991, 45, 50.
10. Kauppinen, J. K.; Moffatt, D. J.; Hollberg, M. R.; Mantsch, H. H.; Appl. Spectrosc. 1991, 45, 411.

11. Saarinen, P. E.; Appl. Spectrosc. 1997, 51, 188.

12. Lórenz-Fonfría, V. A.; Padrós, E.; Spectrochim. Acta, A 2004, 60, 2703.

13. Moffatt, D. J.; Kauppinen, J. K.; Mantsch, H. H.; Can. J. Chem. 1991, 69, 1781.

14. Holler, F.; Burns, D. H.; Appl. Spectrosc. 1989, 43, 877.

15. Fleissner, G.; Hage, W; Hallbrucker, A.; Mayer, E.; Appl. Spectrosc. 1996, 50, 1235.

16. Wentzell, P. D.; Brown, C. D. In Encyclopedia of Analytical Chemistry; Meyers, R. A., ed.; John Wiley \& Sons: Chichester, 2000, 9764.

17. Maddams, W. F.; Appl. Spectrosc. 1980, 34, 245.

18. Vandegiste, B. G. M.; De Galan, L.; Anal. Chem. 1975, 47, 2124.

19. de Aragão, B. J. G.; PhD Thesis, Universidade Estadual Paulista, Araraquara, Brazil, 2006.

20. Yuce, H. H.; Wei, T.; Estes, R.; Wieczorek, C. J.; Devlin, B. T.; Kilmer, J. P.; Varachi, J. P.; Proceedings $41^{\text {st }}$ International Wire \& Cable Symposium, Reno, USA, 1992.

21. Yuce, H. H.; Proceedings $41^{\text {st }}$ International Wire \& Cable Symposium, Reno, USA, 1992.

22. Frantz, R. A.; Keon, B. J.; Vogel, E. M.; Bowmer, T. N.; Yuce, H. H.; Proceedings $43^{\text {rd }}$ International Wire \& Cable Symposium, Atlanta, USA, 1994.

23. Rondinella, V. V.; Matthewson, M. J.; Proceedings of SPIE 2074, Piscataway, USA, 1994.

24. Tomozawa, M.; Hepburn, R.W.; J. Non-Cryst. Solids 2004, 345, 449.

25. de Aragão, B. J. G.; RTI Redes, Telecom e Instalações 2000, 1, 54.

26. Navarra. G.; Iliopoulos, I.; Militello, V.; Rotolo, S. G.; Leone, M.; J. Non-Cryst. Solids 2005, 351, 1796.

27. Nogami, M.; Tomozawa, M.; J. Am. Ceram. Soc. 1984, 67, 151.

28. Burneau, A.; Lepage, J.; Maurice, G.; J. Non-Cryst. Solids 1997, 217,1 .

Received: May 28, 2008

Web Release Date: October 2, 2008

FAPESP helped in meeting the publication costs of this article. 


\title{
Peak Separation by Derivative Spectroscopy Applied to FTIR Analysis of Hydrolized Silica
}

\author{
Bernardo J. G. de Aragão ${ }^{*, a}$ and Younes Messaddeq ${ }^{b}$ \\ ${ }^{a}$ Fundação CPqD, Rod. SP 340 Campinas-Mogi Mirim, km 118, 13086-902 Campinas-SP, Brazil \\ ${ }^{b}$ Instituto de Química, Universidade Estadual Paulista, R. Francisco Degni s/n, 14800-900 Araraquara-SP, Brazil
}

\section{Supplement 1: Analysis of Spectrum 1 (Unaged fiber)}

\section{Shoulder and detection limit maps}

From the data of Table 2 and Table 4 of the original paper follows the calculation of the values of $\mathrm{R}, \varphi$ and $\delta$, which are given in Table $\mathrm{S} 1$.

Table S1. Values of R, $\varphi$ and $\delta$

\begin{tabular}{lccc}
\hline Overlapping peaks/ $\left(\mathrm{cm}^{-1}\right)$ & $\delta$ & $\mathrm{R}$ & $\varphi$ \\
\hline $3635.46 / 3475.96^{\mathrm{a}}$ & 1.89 & 0.87 & 1.7 \\
$3475.96 / 3284.95^{\mathrm{a}, \mathrm{b}}$ & 1.75 & 0.61 & 1.0 \\
$3284.95 / 3122.90^{\mathrm{a}, \mathrm{b}}$ & 2.18 & 0.25 & 1.6 \\
$3675.50 / 3612.15^{\mathrm{b}}$ & 1.18 & 0.53 & 1.2 \\
$3612.15 / 3475.96^{\mathrm{b}}$ & 1.81 & 0.79 & 1.7 \\
\hline
\end{tabular}

${ }^{a}$ Valid for Model I and ${ }^{b}$ Valid for modified Model I.

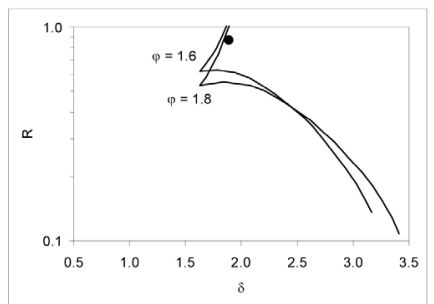

(a) $3635.46 / 3475.96 \mathrm{~cm}^{-1}$

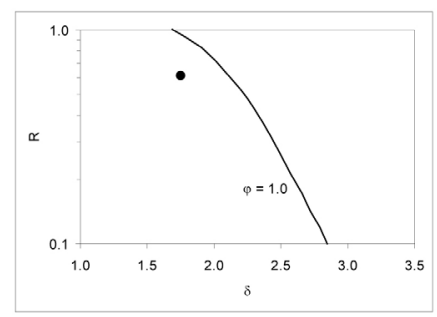

(b) $3475.96 / 3284.95 \mathrm{~cm}^{-1}$

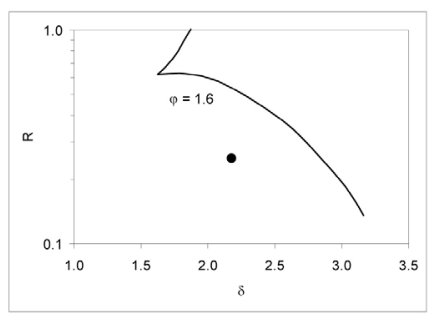

(c) $3284.95 / 3122.90 \mathrm{~cm}^{-1}$

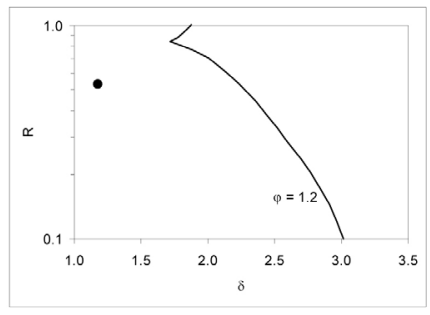

(d) $3675.50 / 3612.15 \mathrm{~cm}^{-1}$
Figure S1 shows the shoulder limit map for the field aged fibers. The Model I is analyzed from (a) to (c). The $3635.46 / 3475.96 \mathrm{~cm}^{-1}$ overlapping peaks (a) are just over the shoulder limit (the limiting line for $\varphi=1.7$ lies between $\varphi=1.6$ and $\varphi=1.8$ ), which means that they can still be visually distinguished. All other pairs of overlapping peaks ((b) and (c)) cannot do so, since they are under the shoulder limit. This is confirmed by Figure 4 of the paper.

Using the modified Model I, the peak at $3635.46 \mathrm{~cm}^{-1}$ is substituted by two peaks at 3675.50 and $3612.15 \mathrm{~cm}^{-1}$ which are not visually resolved (Figure S1 (d) and (e)). It is interesting to note that the $3612.15 / 3475.96 \mathrm{~cm}^{-1}$ overlapping peaks are beyond the detection limit but do not show up in the second derivative. The reason is that the $3612.15 \mathrm{~cm}^{-1}$ peak cannot be detected separately from the $3675.50 \mathrm{~cm}^{-1}$ peak, as shown in Figure S2.

Figure S1. Shoulder limit.

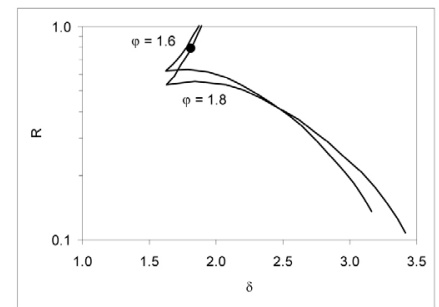

(e) $3612.15 / 3475.96 \mathrm{~cm}^{-1}$

*e-mail: grbernardo@cpqd.com.br, younes@iq.unesp.br 


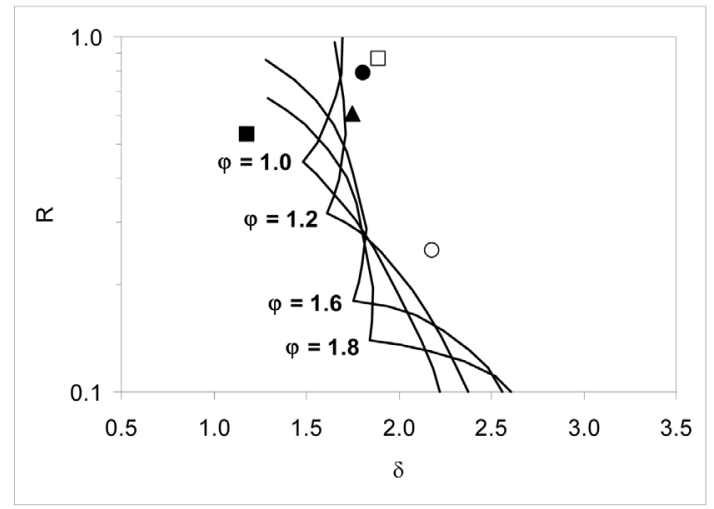

$$
\begin{aligned}
& \text { - } 3675.50 / 3612.15 \mathrm{~cm}^{-1} \quad-3612.15 / 3475.96 \mathrm{~cm}^{-1} \\
& \text { A } 3475.96 / 3284.95 \mathrm{~cm}^{-1} \quad \square 3635.46 / 3475.96 \mathrm{~cm}^{-1}
\end{aligned}
$$$$
3284.95 / 3122.90 \mathrm{~cm}^{-1}
$$

Figure S2. Detection limit.

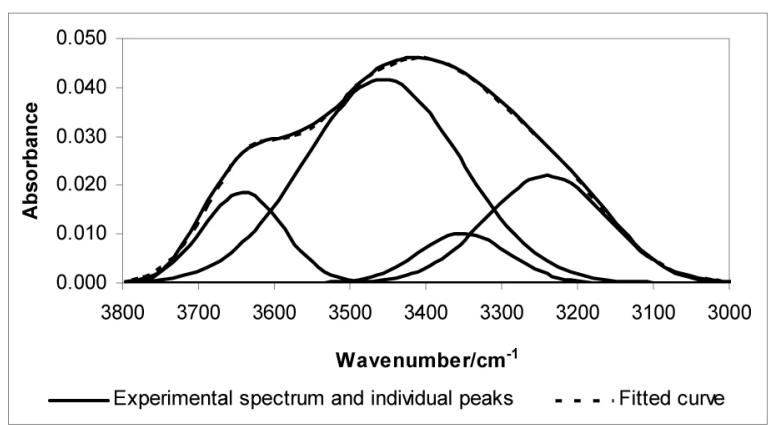

(a) Model I

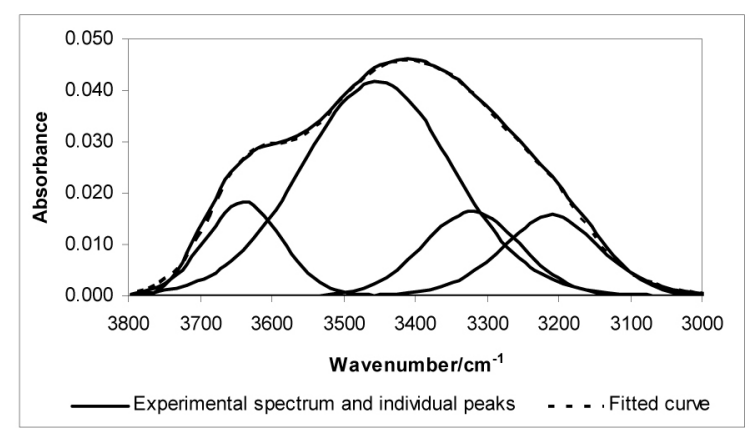

(c) Model III

\section{Supplement II: Analysis of Spectrum 2 (Field aged fiber)}

Curve fitting according to Model I to IV

From Model I to Model III, differences were observed mainly in peak height at 3340 and at $3200 \mathrm{~cm}-1$. Model IV yielded the worst fit (Figure S3). The numerical results are given in Table S2.

\section{Shoulder and detection limit maps}

From the data of Table S2 and Table 7 of the original paper follows the calculation of the values of $\mathrm{R}, \varphi$ and $\delta$, which are given in Table S3.

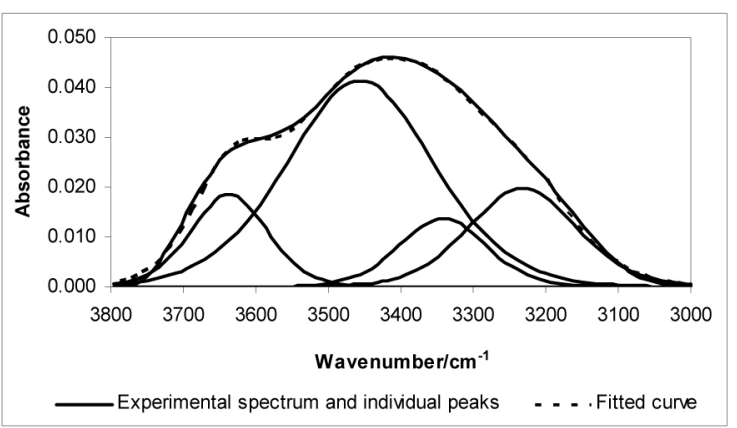

(b) Model II

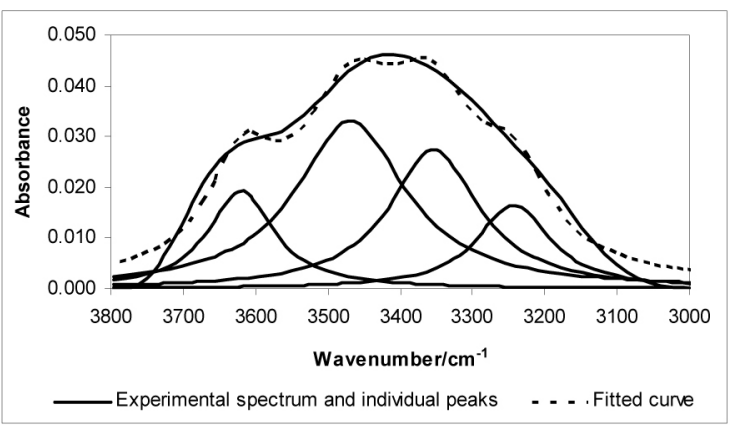

(d) Model IV

Figure S3. Curve fitting results. 
Table S2. Numerical results of curve fitting

\begin{tabular}{|c|c|c|c|c|c|}
\hline Initial guess for peak maximum & Parameter & Model I & Model II & Model III & Model IV \\
\hline \multirow[t]{4}{*}{$3640 \mathrm{~cm}^{-1}$} & $v_{0}\left(\mathrm{~cm}^{-1}\right)$ & 3641.28 & 3637.10 & 3639.35 & 3619.23 \\
\hline & A & 0.0186 & 0.0185 & 0.0182 & 0.0193 \\
\hline & $\mathrm{s}\left(\mathrm{cm}^{-1}\right)$ & 75.25 & 101.06 & 90.00 & 55.09 \\
\hline & $\mathrm{s}^{\prime}\left(\mathrm{cm}^{-1}\right)$ & - & - & 132.53 & - \\
\hline \multirow[t]{4}{*}{$3450 \mathrm{~cm}^{-1}$} & $v_{0}\left(\mathrm{~cm}^{-1}\right)$ & 3456.64 & 3455.89 & 3453.11 & 3468.41 \\
\hline & A & 0.0416 & 0.0414 & 0.0417 & 0.0330 \\
\hline & $\mathrm{s}\left(\mathrm{cm}^{-1}\right)$ & 145.52 & 193.93 & 173.21 & 92.07 \\
\hline & $\mathrm{s}^{\prime}\left(\mathrm{cm}^{-1}\right)$ & - & - & 274.09 & - \\
\hline \multirow[t]{4}{*}{$3340 \mathrm{~cm}^{-1}$} & $v_{0}\left(\mathrm{~cm}^{-1}\right)$ & 3350.13 & 3341.63 & 3320.92 & 3353.53 \\
\hline & A & 0.0102 & 0.0138 & 0.0164 & 0.0275 \\
\hline & $\mathrm{s}\left(\mathrm{cm}^{-1}\right)$ & 83.64 & 114.48 & 100.00 & 75.06 \\
\hline & $\mathrm{s}^{\prime}\left(\mathrm{cm}^{-1}\right)$ & - & - & 349.82 & - \\
\hline \multirow[t]{4}{*}{$3200 \mathrm{~cm}^{-1}$} & $v_{0}\left(\mathrm{~cm}^{-1}\right)$ & 3240.04 & 3231.77 & 3210.50 & 3242.51 \\
\hline & A & 0.0220 & 0.0198 & 0.0158 & 0.0164 \\
\hline & $\mathrm{s}\left(\mathrm{cm}^{-1}\right)$ & 113.05 & 142.92 & 141.42 & 61.81 \\
\hline & $\mathrm{s}^{\prime}\left(\mathrm{cm}^{-1}\right)$ & - & - & 117.38 & - \\
\hline
\end{tabular}

${ }^{a}$ Unit $\left(\mathrm{cm}^{-1}\right), v_{0}$ - peak maximum, s - peak width and s' - the bandwidth term of the Lorentzian part, except A. A - peak height.

Table S3. Values of R, $\varphi$ and $\delta$

\begin{tabular}{lccc}
\hline Overlapping peaks $\left(\mathrm{cm}^{-1}\right)$ & $\delta$ & $\mathrm{R}$ & $\varphi$ \\
\hline $3641.28 / 3457.25^{\mathrm{a}}$ & 2.24 & 0.45 & 1.9 \\
$3680.53 / 3622.16^{\mathrm{b}}$ & 1.17 & 0.42 & 1.4 \\
$3622.13 / 3457.25^{\mathrm{b}}$ & 2.09 & 0.42 & 1.9 \\
$3457.25 / 3319.49^{\mathrm{a}, \mathrm{b}}$ & 1.42 & 0.53 & 1.3 \\
$3319.49 / 3204.75^{\mathrm{a}, \mathrm{b}}$ & 1.41 & 0.70 & 1.1 \\
\hline
\end{tabular}

a valid for Model I, ${ }^{\mathrm{b}}$ valid for modified Model I.
Figure IV shows the shoulder limit map for the field aged fibers. The Model I is analyzed from (a) to (c). The $3641.28 / 3457.25 \mathrm{~cm}^{-1}$ overlapping peaks (A) are under but close to the shoulder limit (the limiting line for $\varphi=1.9$ lies between $\varphi=1.8$ and $\varphi=2.0$ ), which means that they are close to the limit of visual distinction. All other pairs of overlapping peaks ((b) and (c)) cannot be visually distinguished, since they are under the shoulder limit. This is confirmed by Figure 7 of the paper. The overlapping

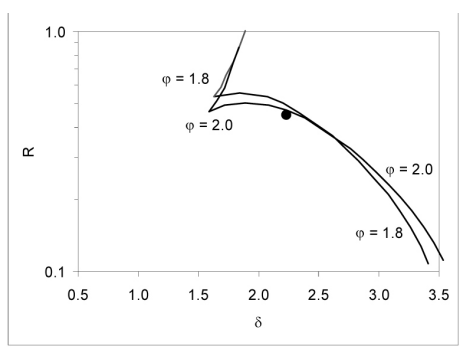

(a) $3641.28 \mathrm{~cm}^{-1} / 3457.25 \mathrm{~cm}^{-1}$

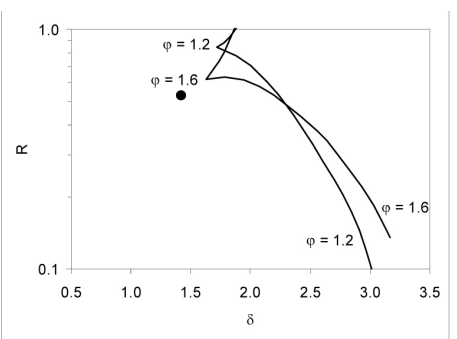

(b) $3457.25 \mathrm{~cm}^{-1} / 3319.49 \mathrm{~cm}^{-1}$

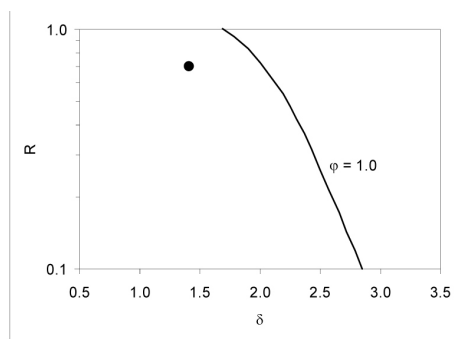

(c) $3319.49 \mathrm{~cm}^{-1} / 3204.75 \mathrm{~cm}^{-1}$

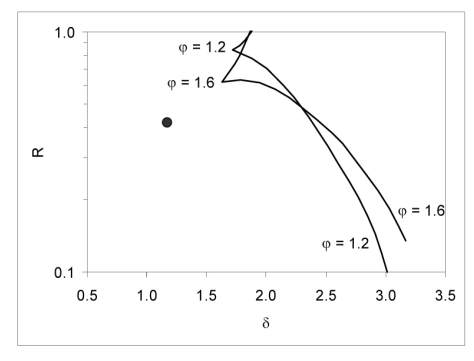

(d) $3680.53 \mathrm{~cm}^{-1} / 3622.13 \mathrm{~cm}^{-1}$

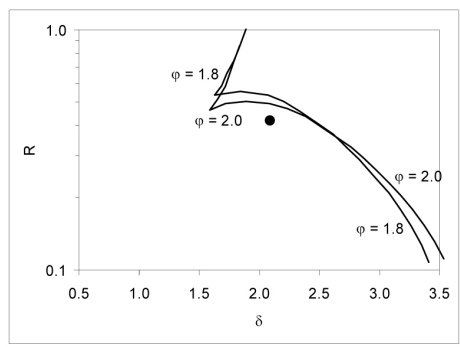

(e) $3622.13 \mathrm{~cm}^{-1} / 3457.25 \mathrm{~cm}^{-1}$

Figure S4. Shoulder limit. 
peaks at $3457.25 / 3319.49 \mathrm{~cm}^{-1}$ and $3319.49 / 3204.75 \mathrm{~cm}^{-1}$ are also under the detection limit (Figure S5). As seen in Figure 7 of the paper, the peak at $3319.49 \mathrm{~cm}^{-1}$ is barely

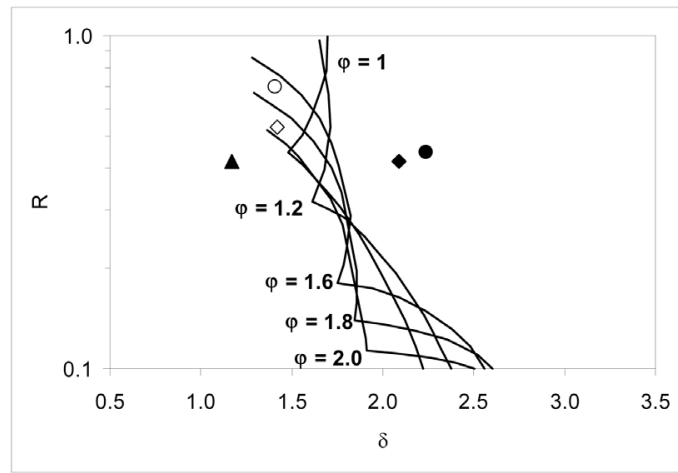

$$
\begin{gathered}
\Delta 3680.53 \mathrm{~cm}^{-1} / 3622.13 \mathrm{~cm}^{-1} \bullet 3622.13 \mathrm{~cm}^{-1} / 3457.25 \mathrm{~cm}^{-1} \\
\diamond 3457.25 \mathrm{~cm}^{-1} / 3319.49 \mathrm{~cm}^{-1} \quad 03319.49 \mathrm{~cm}^{-1} / 3204.75 \mathrm{~cm}^{-1} \\
\bullet 3641.28 \mathrm{~cm}^{-1} / 3457.25 \mathrm{~cm}^{-1}
\end{gathered}
$$

Figure S5. Detection limit.

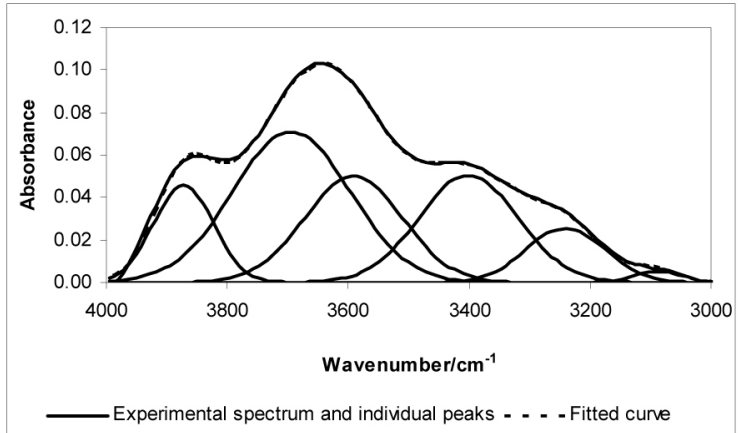

(a) Model I

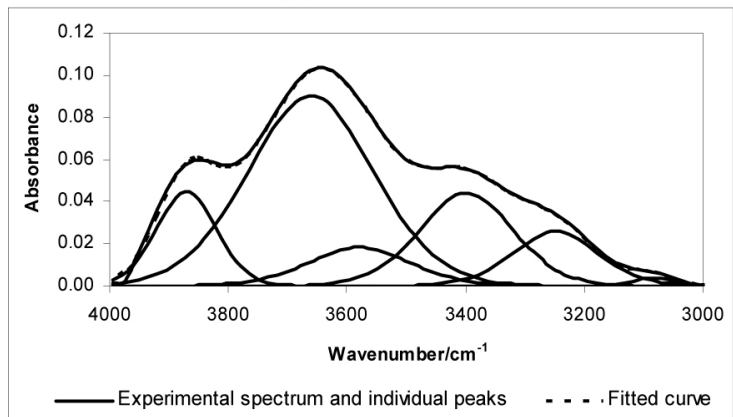

(c) Model III visible in the second derivative and its existence is only confirmed by the fourth derivative.

Using the modified Model I, the peak at $3641.28 \mathrm{~cm}^{-1}$ is substituted by two peaks at $3680.53 / 3622.13 \mathrm{~cm}^{-1}$ which are not visually resolved (Figure S4 (d) and (e)). It is interesting to note that the $3622.13 / 3457.25 \mathrm{~cm}^{-1}$ overlapping peaks are beyond the detection limit but do not show up in the second derivative. The reason is that the $3622.13 \mathrm{~cm}^{-1}$ peak cannot be detected separately from the $3680.53 \mathrm{~cm}^{-1}$ peak, as shown in Figure S5.

\section{Supplement III: Analysis of Spectrum 3 (14 days ageing at room temperature and under compressive stress of $0.5 \mathrm{GPa}$ )}

Curve fitting according to Model I to IV

Figure S6 shows the experimental spectrum, together with the separated peaks and the fitted curve, for all curve fitting models. The numerical results are given in Table S4.

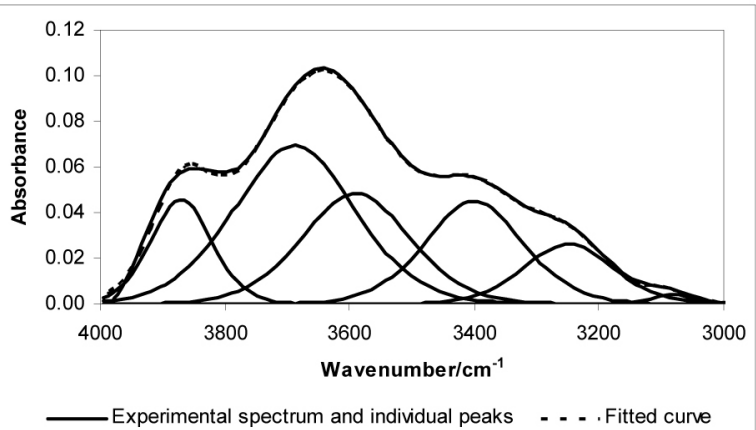

(b) Model II

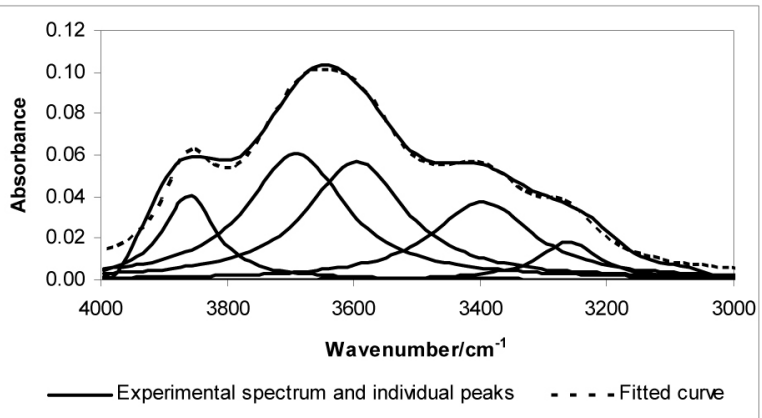

(d) Model IV

Figure S6. Curve fitting results. 
Table S4. Numerical results of curve fitting

\begin{tabular}{|c|c|c|c|c|c|}
\hline Initial guess for peak maximum & Parameter & Model I & Model II & Model III & Model IV \\
\hline \multirow[t]{4}{*}{$3900 \mathrm{~cm}^{-1}$} & $v_{0}\left(\mathrm{~cm}^{-1}\right)$ & 3872.51 & 3869.89 & 3870.35 & 3859.98 \\
\hline & A & 0.0456 & 0.0457 & 0.0448 & 0.0409 \\
\hline & $\mathrm{s}\left(\mathrm{cm}^{-1}\right)$ & 70.24 & 95.25 & 90.00 & 49.60 \\
\hline & $\mathrm{s}^{\prime}\left(\mathrm{cm}^{-1}\right)$ & - & - & 109.29 & - \\
\hline \multirow[t]{4}{*}{$3700 \mathrm{~cm}^{-1}$} & $v_{0}\left(\mathrm{~cm}^{-1}\right)$ & 3694.04 & 3688.00 & 3660.73 & 3690.22 \\
\hline & A & 0.0710 & 0.0695 & 0.0901 & 0.0612 \\
\hline & $\mathrm{s}\left(\mathrm{cm}^{-1}\right)$ & 136.61 & 184.45 & 181.66 & 92.45 \\
\hline & $\mathrm{s}^{\prime}\left(\mathrm{cm}^{-1}\right)$ & - & - & 250.51 & - \\
\hline \multirow[t]{4}{*}{$3600 \mathrm{~cm}^{-1}$} & $v_{0}\left(\mathrm{~cm}^{-1}\right)$ & 3591.25 & 3590.32 & 3579.78 & 3595.42 \\
\hline & A & 0.0500 & 0.0485 & 0.0183 & 0.0572 \\
\hline & $\mathrm{s}\left(\mathrm{cm}^{-1}\right)$ & 114.34 & 165.22 & 164.32 & 93.59 \\
\hline & $\mathrm{s}^{\prime}\left(\mathrm{cm}^{-1}\right)$ & - & - & 168.69 & - \\
\hline \multirow[t]{4}{*}{$3400 \mathrm{~cm}^{-1}$} & $v_{0}\left(\mathrm{~cm}^{-1}\right)$ & 3400.91 & 3400.17 & 3398.63 & 3396.76 \\
\hline & A & 0.0505 & 0.0449 & 0.0443 & 0.0377 \\
\hline & $\mathrm{s}\left(\mathrm{cm}^{-1}\right)$ & 115.74 & 151.10 & 148.32 & 95.94 \\
\hline & $\mathrm{s}^{\prime}\left(\mathrm{cm}^{-1}\right)$ & - & - & 151.98 & - \\
\hline \multirow[t]{4}{*}{$3250 \mathrm{~cm}^{-1}$} & $v_{0}\left(\mathrm{~cm}^{-1}\right)$ & 3241.20 & 3248.77 & 3248.35 & 3260.80 \\
\hline & A & 0.0257 & 0.0262 & 0.0263 & 0.0184 \\
\hline & $\mathrm{s}\left(\mathrm{cm}^{-1}\right)$ & 91.96 & 138.13 & 137.84 & 56.73 \\
\hline & $\mathrm{s}^{\prime}\left(\mathrm{cm}^{-1}\right)$ & - & - & 135.25 & - \\
\hline \multirow[t]{4}{*}{$3080 \mathrm{~cm}^{-1}$} & $v_{0}\left(\mathrm{~cm}^{-1}\right)$ & 3087.60 & 3080.93 & 3081.64 & - \\
\hline & A & 0.0053 & 0.0041 & 0.0041 & - \\
\hline & $\mathrm{s}\left(\mathrm{cm}^{-1}\right)$ & 55.67 & 64.89 & 64.81 & - \\
\hline & $\mathrm{s}^{\prime}\left(\mathrm{cm}^{-1}\right)$ & - & - & 70.28 & - \\
\hline
\end{tabular}

aUnit $\left(\mathrm{cm}^{-1}\right), v_{0}$ - peak maximum, s - peak width and s' - the bandwidth term of the Lorentzian part, except A. A - peak height. 